\title{
Interannual Variability of the Overturning and Energy Transport in the Atmosphere and Ocean During the Late Twentieth Century with Implications for Precipitation and Sea Level
}

\author{
MAGNUS HIERONYMUS \\ Swedish Meteorological and Hydrological Institute, Norrköping, and Department of Meteorology, Stockholm University, \\ Stockholm, Sweden \\ JONAS NYCANDER \\ Department of Meteorology, Stockholm University, Stockholm, Sweden
}

(Manuscript received 14 March 2019, in final form 21 August 2019)

\begin{abstract}
The overturning circulations in the atmosphere and ocean transport energy from the tropics to higher latitudes and thereby modulate Earth's climate. The interannual variability in the overturning over the last 40 years is found to be dominated by two coupled atmosphere-ocean modes. The first is related to the meridional motion of the intertropical convergence zone and the second to El Niño. Both modes have a strong influence on the sea level variability in the tropical Indo-Pacific Ocean. The interannual variability of the crossequatorial energy transport is dominated by the first mode, and the variability is larger in the Indo-Pacific Ocean than in the Atlantic Ocean or the atmosphere. Our results suggest an important role of oceanic energy transport in setting precipitation patterns in the tropics and a key role of the Indo-Pacific Ocean as a climate modulator.
\end{abstract}

\section{Introduction}

The meridional overturning circulations (MOCs) in the ocean and atmosphere are large-scale circulation systems whose energy transport profoundly affects our climate. Interannual variations in the MOCs influence the planetary meridional energy transport that redistributes heat from the tropics to higher latitudes, affecting large-scale weather patterns and society as a whole. The atmospheric and oceanic MOCs and meridional energy transport have traditionally most often been treated separately, even though it is well known that at least their tropical parts are strongly coupled (Held 2001; Czaja and Marshall 2006; Nilsson and Körnich 2008; Vallis and Farneti 2009). The ocean overturning in the Northern Hemisphere, which is separated into the Indo-Pacific and the Atlantic basins, is in contrast often treated jointly, even though the overturning characteristics in the two basins are rather different (Talley 2013; Ferrari et al. 2014). Moreover, when the two basins are separated, the Atlantic MOC

Corresponding author: Magnus Hieronymus, hieronymus.magnus@ gmail.com
(AMOC), with its greater time mean energy transport and long-term climate impact, has sparked much more research interest in the oceanographic community than that in the Indo-Pacific Ocean (here defined as the entire Indian and Pacific Oceans north of $30^{\circ} \mathrm{S}$ ). We will demonstrate here that the Indo-Pacific MOC is much more strongly coupled to the atmospheric circulation and that it dominates the interannual variability of the crossequatorial energy transport.

The time mean overturning, precipitation, and energy transport in the atmosphere and Indo-Pacific Ocean between the years 1979 and 2017 are shown in Fig. 1. Note that the atmospheric streamfunction is calculated over the entire atmosphere and not just the part above the Indo-Pacific Ocean; see the methods section for more details. The figure is based on reanalysis data from the European Centre for Medium-Range Weather Forecasts (ECMWF), more specifically, ERA-Interim data (Dee et al. 2011) for the atmosphere and Ocean Reanalysis System, version 4 (ORAS4), data (Balmaseda et al. 2013) for the ocean. Both reanalyses are derived from model integrations constrained by data assimilation from a wide range of observations and constitute a best 

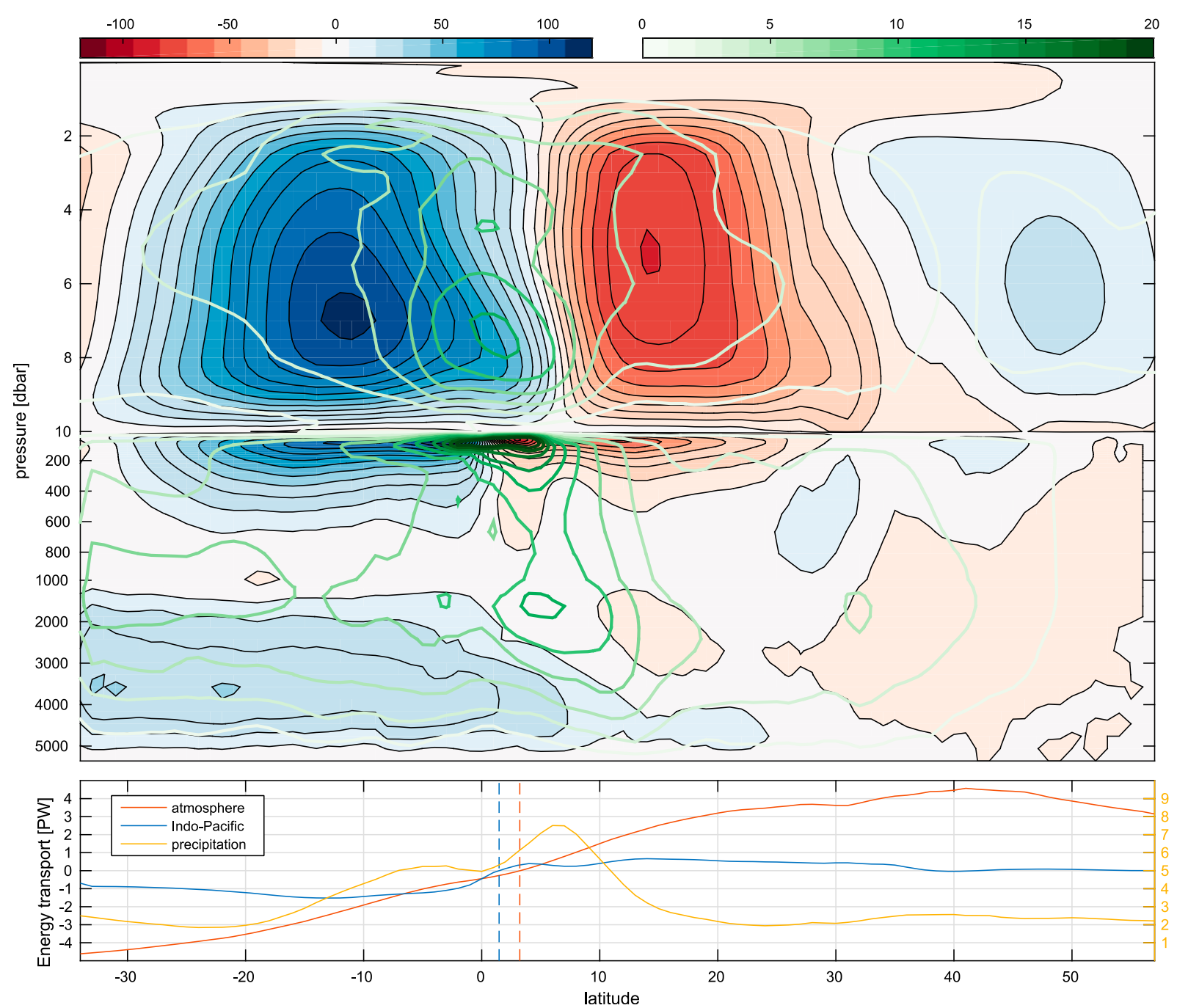

FIG. 1. 1979-2017 average atmospheric and Indo-Pacific (top) overturning streamfunctions and (bottom) meridional energy transport and global precipitation. Green contours in the top panel show the standard deviation of the yearly averages of the overturning streamfunction. The streamfunctions are in units of Sverdrups $\left(1 \mathrm{~Sv}=10^{9} \mathrm{~kg} \mathrm{~s}^{-1}\right)$, and the oceanic overturning has been multiplied by a factor of 3 to make the color scales comparable. The latitudes where the mean energy transports in the atmosphere and ocean are zero are marked with dashed vertical lines. A negative (positive) sign indicates a clockwise (anticlockwise) circulation

estimate of the current and past state of the atmosphere and ocean. The atmospheric overturning is dominated by the Hadley cells, with a maximum amplitude in excess of $100 \mathrm{~Sv}$ [here we use mass Sverdrups, $1 \mathrm{~Sv}=$ $10^{9} \mathrm{~kg} \mathrm{~s}^{-1}$, following Czaja and Marshall (2006)]. The ascending branch of this circulation is collocated with the intertropical convergence zone (ITCZ), and can be identified with the precipitation maximum shown in the lower panel.

The oceanic analogy of the Hadley cells is the subtropical cells (STCs) that occupy the latitudes between $30^{\circ} \mathrm{S}$ and $30^{\circ} \mathrm{N}$ and pressures between 10 and $500 \mathrm{db}$ (depths between 0 and $500 \mathrm{~m}$ ). The strength of the oceanic circulation is about a third of the atmospheric one and has been multiplied by a factor of 3 to improve the visualization. The ascending branch of the STCs is, in contrast to its atmospheric counterpart, located at the equator and fixed by the equatorial divergence of the wind-driven Ekman transport. Apart from the STCs there is also a deep, mixing driven, overturning cell where northward flowing cold and dense Antarctic Bottom Water (AABW) upwells and returns southward (Marshall and Speer 2012; de Lavergne et al. 2017; Hieronymus et al. 2019).

The meridional energy transport is dominated by the atmosphere except for in the deep tropics, where the ocean dominates owing to a larger energy contrast between the upper and lower branch of the overturning 
cell (Held 2001; Czaja and Marshall 2006). Both the atmospheric and oceanic energy transports in the deep tropics are dominated by the overturning cells, and the transport is in the same direction as the mass transport in their upper branches. A consequence of this is that the atmosphere transports energy away from the Northern Hemisphere where the time mean ITCZ resides. The time mean ITCZ is situated in the hemisphere most strongly heated by radiative and turbulent surface and top of the atmosphere energy fluxes (Green and Marshall 2017), and the time mean placement of the ITCZ in the Northern Hemisphere has been attributed to the northward energy transport in the Atlantic Ocean (Frierson et al. 2013; Marshall et al. 2014). The ITCZ position also coincides with the so-called energy flux equator, which is the latitude where the atmospheric meridional energy transport changes sign (Kang et al. 2008). This connection has been used to relate the position of the ITCZ to the atmospheric cross-equatorial energy transport and the net heating of the equatorial atmosphere from top of the atmosphere and surface energy fluxes (Bischoff and Schneider 2014; Schneider et al. 2014; Bischoff and Schneider 2016; Kang et al. 2018).

Interannual variations in the atmospheric energy transport and overturning are, like their time mean components, strongly linked to the position of the ITCZ (Donohoe et al. 2013, 2014; Liu et al. 2017). Donohoe et al. (2014) quantified the relation between the ITCZ position and the atmospheric cross-equatorial energy transport $\left(F_{A}\right)$ using the centroid of zonally averaged precipitation $\left(P_{\text {cent }}\right)$ between the latitudes $20^{\circ} \mathrm{S}$ and $20^{\circ} \mathrm{N}$ as a proxy for the ITCZ position. On interannual time scales they found a strong negative correlation of $r=-0.75$ between $F_{A}$ and $P_{\text {cent }}$ in the NCEP-NCAR reanalysis. More recently, however, Adam et al. (2016) found $F_{A}$ and $P_{\text {cent }}$ to be weakly correlated in the ERAInterim reanalysis on interannual time scales. Here we will try to reconcile these two estimates.

Donohoe et al. (2014) also quantified the correlation between the energy transport in the Atlantic Ocean $\left(F_{O}^{\text {Atl }}\right)$ and $P_{\text {cent }}$ and found it to be weak. This result led them to exclude the possibility of an oceanic influence on the ITCZ migrations on interannual time scales. More recent work has, however, shown that when the hemispheric radiative energy balance is perturbed, the oceanic energy transport often changes more than the atmospheric one, giving rise to an oceanic damping on ITCZ migrations (Green and Marshall 2017; Kay et al. 2016; Tomas et al. 2016; Hawcroft et al. 2017). However, the partitioning of such anomalous energy transports between the ocean and atmosphere has been found to depend on the latitude where the forcing is applied, which generally gives a more ocean-centric response for high-latitude perturbations (Hawcroft et al. 2018; Xiang et al. 2018; Liu et al. 2018; Yu and Pritchard 2019; Green et al. 2019). The partitioning of the oceanic energy transport into its Indo-Pacific and Atlantic constituents is also perturbation dependent, where the Atlantic contribution is small for low-latitude perturbations but sizable for high-latitude perturbations (Yu and Pritchard 2019; Green et al. 2019).

The large body of work on the connection between the atmospheric energy budget and the ITCZ position that we briefly reviewed above mainly focuses on equilibrium or near-equilibrium responses to various perturbations applied to climate models, with a few exceptions. Our work here is instead focused on the interannual variability of the real climate system. Using empirical orthogonal functions (EOFs) (Hannachi et al. 2007; Monahan et al. 2009) and maximum covariance analysis (MCA) (Bretherton et al. 1992; Czaja and Frankignoul 2002), we investigate the connections between the ITCZ position, the atmospheric energy transport, the oceanic energy transport, and the leading modes of variability in the atmospheric and IndoPacific overturning circulation on interannual time scales.

\section{Methods and data}

\section{a. Data}

Our atmospheric data come from the ERA-Interim reanalysis (Dee et al. 2011) covering the years 1979-2017. The data have a six-hourly temporal resolution and have been interpolated onto 37 pressure levels in the vertical and a horizontal grid with $1^{\circ}$ resolution. The ocean reanalysis data come from two sources. The first is the ORAS4 reanalysis (Balmaseda et al. 2013), from which we use data from the years 1979-2017. The output variables are monthly means on a vertical grid of 42 constant depth levels with a nominal horizontal resolution of $1^{\circ}$. The second ocean reanalysis is the ECCO, version $4 \mathrm{r} 3$ (V4r3), state estimate (Forget et al. 2015; Fukumori et al. 2017), which covers the years 1992-2015. The output variables are monthly means with a nominal horizontal resolution of $1^{\circ}$, and with 50 constant depth levels in the vertical. The use of these two ocean reanalyses is motivated by the fact that both of them use the ERA-Interim data as part of their surface forcing, which should give us as consistent results as possible in the absence of a truly coupled reanalysis. However, we also note that the ERAInterim data are altered in the ECCO-V4r3 state estimate to allow for better tracer conservation and consistency with the ocean dynamics. We also use satellite-based sea level data from the SSALTO/Data Unification and Altimeter Combination System (DUACS) all-satellitemerged product [distributed by the Copernicus Marine 
Environment Monitoring Service (CMEMS); http:// marine.copernicus.eu], which provides daily output of sea level anomalies on a horizontal grid with $1 / 4^{\circ}$ resolution.

\section{b. Methods}

In our calculations we equate the atmospheric energy transport $\left(F_{A}\right)$ with the moist static energy (MSE) transport. That is, we ignore the small contribution from kinetic energy. Yearly averages of $F_{A}$ are then calculated from the six-hourly ERA-Interim data following Mayer et al. (2017) as

$$
\begin{aligned}
F_{A}= & \frac{1}{g\left(t_{1}-t_{0}\right)} \int_{t_{0}}^{t_{1}} \int_{x} \int_{p_{s}}^{0} v\left[(1-q) c_{a}\left(T_{a}-T_{00}\right)\right. \\
& \left.+L_{v}\left(T_{a}\right) q+\phi\right] d p d x d t,
\end{aligned}
$$

where $g$ is the gravitational acceleration, $t_{1}-t_{0}$ is the time span of one year, $p_{s}$ is the surface pressure, $q$ is the specific humidity, $c_{a}$ is the specific heat of dry air at constant pressure, $T_{a}$ is the temperature in $\mathrm{K}, T_{00}=$ $273.15 \mathrm{~K}, L_{v}$ is the latent heat of vaporization, $\phi$ is the geopotential, and $v$ is the meridional velocity, which has been corrected to conserve dry mass through the addition of a barotropic velocity (Trenberth 1991; Mayer and Haimberger 2012). The zonal integration in Eq. (1) is carried out over all longitudes. The above formulation improves on the most commonly used MSE formulation by consistently neglecting enthalpy fluxes due to precipitation and evaporation, and our cross-equatorial energy transports have also been checked for consistency with those of Mayer et al. (2017).

$F_{A}$ is also split into contributions from the mean meridional circulation, stationary eddies and transient eddies according to

$$
F_{A}=\langle[\bar{v}][\overline{\mathrm{MSE}}]\rangle+\left\langle\left[\bar{v}^{*} \overline{\mathrm{MSE}^{*}}\right]\right\rangle+\left\langle\left[\overline{\boldsymbol{v}^{\prime} \mathrm{MSE}^{\prime}}\right]\right\rangle,
$$

where angle brackets signify mass weighted vertical integration in pressure coordinates and multiplication by the circumference of Earth; overlines and square brackets denote time and zonal averages, respectively; asterisks and primes signify departures from the zonal and temporal averages, respectively; and MSE is the sum of the latent heat, sensible heat, and the geopotential defined as in Eq. (1). The time averaging here is done over calendar years as in Eq. (1), which implies that variability on time scales shorter than one year is labeled as transient eddies. Throughout this paper we use yearly averages in all our analyses, and it is worth noting that the way the temporal averaging is done can affect the results. In the case of transient eddies discussed above the effect is obvious. However, the effect of taking a yearly average of a climate index is not so obvious. For example, Sullivan et al. (2016) studied the spectral properties of various central Pacific and eastern Pacific El Niño indices, and found that the central Pacific indices had spectral peaks on a decadal time scale of about 10 years, and rather weak interannual variability. Taking a yearly average of such an index could smooth out the interannual variability so much that it would be hard to detect. What we capture in these analyses is typically the low-frequency part of the interannual variability and even some decadal variability. As a consequence of this, we expect, for example, interannual variability owing to the central Pacific type El Niño to be somewhat suppressed.

The oceanic meridional energy fluxes are calculated from the monthly mean values in the ORAS4 reanalysis according to

$$
F_{O}=\frac{\rho_{0} c_{p}}{t_{1}-t_{0}} \int_{t_{0}}^{t_{1}} \int_{x} \int_{z} \theta v d z d x d t
$$

where $\rho_{0}$ is the reference density, $c_{p}$ is the specific heat, and $\theta$ is the potential temperature. This approach to calculating the meridional energy fluxes ignores the contributions from lateral diffusion and parameterized eddy transport (Gent and McWilliams 1990), which are small apart from in the Southern Ocean (Hieronymus and Nycander 2013). The meridional energy fluxes including the diffusive and parameterized parts are saved at full time resolution in the ECCO-V4r3 state estimate, so no offline calculation is needed to estimate these fluxes. In section $3 \mathrm{~b}$ we will show that the cross-equatorial energy fluxes from these two ocean reanalyses are in excellent agreement despite the methodological differences in their calculation. This indicates that variability on time scales of less than one month as well as diffusive and parameterized transports give only minor contributions to the oceanic crossequatorial energy transport. Similarly to $F_{A}, F_{O}$ can be decomposed into a mean and a transient eddy component according to

$$
F_{O}=\langle[\bar{v} \bar{\theta}]\rangle+\left\langle\left[\overline{\bar{v}^{\prime} \theta^{\prime}}\right]\right\rangle .
$$

The ocean-atmosphere surface fluxes over the IndoPacific Ocean $F_{S}^{\mathrm{IP}}$ from the ORAS4 reanalysis are calculated from the budget:

$$
F_{S}^{\mathrm{IP}}=-\frac{d E_{O}^{\mathrm{IP}}}{d t}+F_{O}^{\mathrm{IP}}
$$

where $E_{O}^{\mathrm{IP}}$ is the energy integrated in the Indo-Pacific Ocean north of the equator, and we have neglected the small energy transports through Bering Strait. The 
surface fluxes are thus calculated as a residual of the cross-equatorial energy transport and the ocean heat uptake. The actual surface fluxes seen by the ocean model used to create ORAS4 are not known to us. Moreover, the assimilation scheme used in ORAS4 does not conserve energy exactly, so the $F_{S}^{\mathrm{IP}}$ implied by Eq. (5) is not necessarily equal to that seen by the model. The surface fluxes from the ECCO-V4r3 estimate are available at full time resolution, so these are simply integrated over the Indo-Pacific Ocean north of the equator to get $F_{S}^{\mathrm{IP}}$. Moreover, energy conservation is enforced in the ECCO-V4r3 estimate through adjustments made to the atmospheric forcing, which makes it less consistent with the ERA-Interim reanalysis. Both our estimates of $F_{S}^{\mathrm{IP}}$ thus have obvious drawbacks, and we do not know which of the two best approximates nature. We therefore treat both as plausible.

The overturning streamfunctions are calculated according to

$$
\Psi(y, p)=\frac{1}{g\left(t_{1}-t_{0}\right)} \int_{t_{0}}^{t_{1}} \int_{x} \int_{p_{s}}^{p} v d p^{\prime} d x d t,
$$

for the atmosphere, where the zonal integration is over all longitudes, and

$$
\Psi(y, z)=\frac{1}{t_{1}-t_{0}} \int_{t_{0}}^{t_{1}} \int_{x} \int_{-H}^{z} v d z^{\prime} d x d t,
$$

for the ocean, where $H$ is the depth of the ocean and the zonal integration is over an ocean basin. The oceanic overturning is mapped into pressure coordinates by assuming that the pressure in decibars equals the depth in meters plus the surface pressure.

The EOFs and the MCA modes are extracted through singular value decomposition (Bretherton et al. 1992) using the svd function in MATLAB. MCA is very similar to EOF analysis, but it can be applied to two datasets simultaneously. We use this technique to extract covariant modes of, for example, oceanic and atmospheric MOC and atmospheric MOC and precipitation. For consistency we have also compared the MCA decomposition of the ocean and atmosphere overturning to the results from an EOF analysis where the two fields are normalized and combined (Bretherton et al. 1992), and the results are in excellent agreement (not shown). We will refer to the spatial modes of the EOF analysis as the EOFs and the temporal expansion coefficients as principal components (PCs). Similarly, we will call spatial modes derived from MCA MC modes and their temporal expansion coefficients PCs. The MCA gives one PC for each mode and dataset. The MCA of the atmospheric MOC and precipitation thus gives two principal components per mode: one for the atmospheric MOC and another for the precipitation.

\section{Results}

\section{a. Overturning variability}

Figure 2 shows the first two MC modes of the overturning circulation in the atmosphere and Indo-Pacific Ocean constructed from yearly averaged streamfunction anomalies. The first mode accounts for $75 \%$ of the explained squared covariance and the second one for another $12 \%$. The atmospheric and oceanic overturning cells both rotate in the same direction, so their cross-equatorial energy transport is also in the same direction (northward when the PC is positive). Also shown are the EOFs of the zonally averaged IndoPacific energy transport and the global precipitation that are most strongly correlated with the two MC modes. The EOFs of the atmospheric energy transport are dominated by midlatitude rather than tropical variability and have therefore been left out. The precipitation, energy transport, and overturning peaks are all approximately collocated, hinting at the role of the overturning cells for the energy transport and precipitation. The peak periods are about three years for the first mode and between four and five years for the second.

The standard deviation of the annual mean overturning streamfunction exceeds $12 \mathrm{~Sv}$ in the atmosphere and $8 \mathrm{~Sv}$ in the ocean (see Fig. 1), and the largest standard deviations are approximately collocated with the respective maxima in the first MC mode. The principal component time series for the first overturning modes (PC1) in the atmosphere (ocean) is strongly anticorrelated with $P_{\text {cent }}$ based on yearly averaged precipitation, having $r=-0.96(r=-0.78)$. Correlation coefficients are also given in Table 1 and the PCs are shown in Fig. 3. Thus, when the PCs are positive, the corresponding energy transport anomalies are directed northward and the ITCZ is displaced southward. Moreover, the mode structure is very similar to the atmospheric streamfunction anomalies shown by Donohoe et al. (2014) and the coupled mode described by Green and Marshall (2017). This cross-equatorial oscillation is consistent with energy transport across the equator in the atmosphere as the ITCZ undulates back and forth. The shallow wind-driven oceanic flow also crosses the equator even though the Ekman balance breaks down there. The circulation is qualitatively similar to the time mean circulation in the Indian Ocean that also crosses the equator, and the cross-equatorial flow is facilitated by an increase/decrease of the wind stress on either side of the equator that weakens the Ekman 


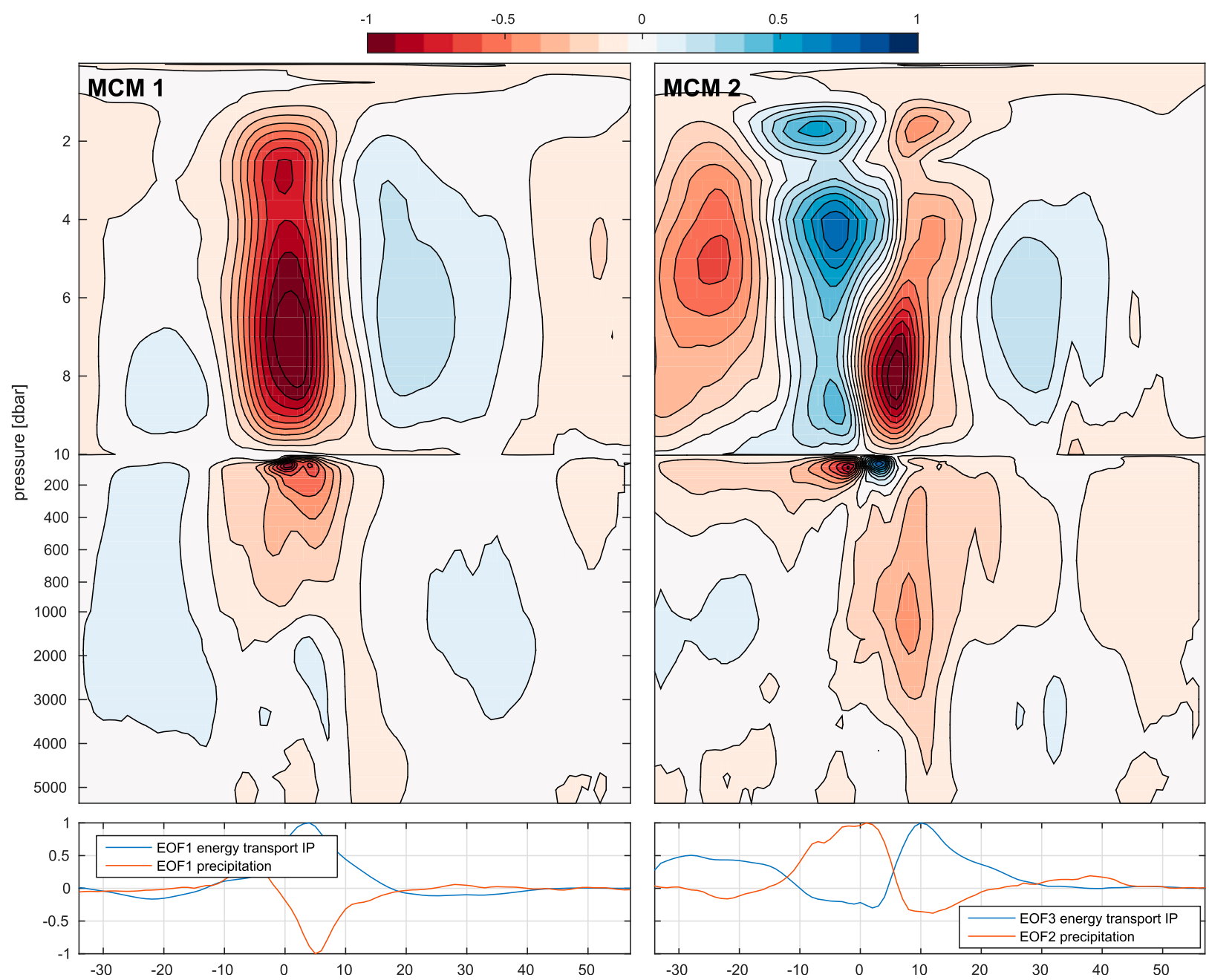

FIG. 2. (top) First and second MC mode of the atmospheric and Indo-Pacific overturning, and (bottom) EOFs of the zonal averages of the Indo-Pacific meridional energy transport and precipitation. The mode decompositions are done on yearly averages of the reanalysis data from the years 1979-2017. Units are normalized to have amplitudes between 0 and 1 . The second EOF of precipitation is correlated to both overturning modes, but more strongly with the second.

transport divergence at the equator (Schott et al. 2002; Miyama et al. 2003; Schott et al. 2009; Green and Marshall 2017).

The second overturning mode covaries with El NiñoSouthern Oscillation (ENSO). The atmospheric (oceanic) PC2 has a correlation coefficient of $r=0.77(r=0.80)$ with the Niño-3.4 index [here calculated from yearly averaged sea surface temperature (SST) in the region $5^{\circ} \mathrm{N}-5^{\circ} \mathrm{S}$, $\left.170^{\circ}-120^{\circ} \mathrm{W}\right]$. The atmospheric pattern is a modulation of the strength and extent of the Hadley cells, where the strength increases and the meridional extent contracts in the warm phase. The existence of such an ENSO response in the Hadley circulation is known (Oort and Yienger 1996; Nguyen et al. 2013). The second oceanic overturning mode consists of a weakening of the STCs in the warm phase, a direct effect of Ekman transport changes due to the weakened trade winds (Merryfield and Boer 2004). There is also a large and deep perturbation centered around $10^{\circ} \mathrm{N}$ that has some similarities to the streamfunction response to turning off the wind stress found by Williams et al. (2014). The standard deviation of the yearly averaged streamfunction in this area exceeds $4 \mathrm{~Sv}$ (see Fig. 1) and the perturbation deepens the northern STC greatly during the warm phase. During normal conditions at $10^{\circ} \mathrm{N}$ there is an approximate balance between the poleward flowing Ekman transport and the equatorward flowing net geostrophic transport above a depth of about $500 \mathrm{~m}$, giving rise to a roughly 500 -m-thick closed STC. Both these flows are expected to weaken during the warm phase. An equatorward Ekman transport anomaly is expected as a result of the weakened trade winds, while a poleward geostrophic transport anomaly is 
TABLE 1. Correlation coefficients between the two indices and the principal components and cross-equatorial energy transports used in this study and their respective $p$ values. The $95 \%$ confidence interval of the correlation coefficients is given in square brackets. Var exp gives the variance explained by the different EOF modes and $\operatorname{cov}^{2}$ exp the squared covariance explained by the MCA modes. ( $)^{a}$ indicates correlation coefficient evaluated between 1984-2016, ( ) $)^{b}$ indicates correlation coefficient evaluated between 1992-2015 (the time frame of the ECCO-V4r3 state estimate), and ( $)^{c}$ indicates correlation coefficient evaluated between 1993 and 2017 (the time frame of the SSALTO/DUACS all-sat-merged product). All other correlations are evaluated over the period 1979-2017. The sea level data are detrended prior to the calculation of the correlation coefficients to remove the effect of mean sea level rise.

\begin{tabular}{|c|c|c|c|c|}
\hline & $P_{\text {cent }}$ & Niño-3.4 & $\begin{array}{l}\text { var } \\
\text { exp }\end{array}$ & $\begin{array}{l}\operatorname{cov}^{2} \\
\exp \end{array}$ \\
\hline $\operatorname{MCA}\left(\mathrm{MOC}_{\mathrm{atm}}-\mathrm{MOC}_{\mathrm{IP}}\right) \mathrm{PC} 1(\mathrm{~atm})$ & $r=-0.96[-0.98,-0.92] p<0.001$ & $r=-0.06[-0.37,0.26] p=0.71$ & & $75 \%$ \\
\hline $\mathrm{MCA}\left(\mathrm{MOC}_{\mathrm{atm}}-\mathrm{MOC}_{\mathrm{IP}}\right) \mathrm{PC1}$ (oce) & $r=-0.78[-0.88,-0.61] p<0.001$ & $r=-0.09[-0.40,0.23] p=0.57$ & & $75 \%$ \\
\hline $\mathrm{MCA}\left(\mathrm{MOC}_{\mathrm{atm}}-\mathrm{MOC}_{\mathrm{IP}}\right) \mathrm{PC}(\mathrm{atm})$ & $r=0.02[0.30,0.33] p<0.91$ & $r=0.77[0.60,0.87] p<0.001$ & & $12 \%$ \\
\hline $\operatorname{MCA}\left(\mathrm{MOC}_{\mathrm{atm}}-\mathrm{MOC}_{\mathrm{IP}}\right) \mathrm{PC} 2$ (oce) & $r=0.04[0.28,0.35] p<0.80$ & $r=0.80[0.65,0.89] p<0.001$ & & $12 \%$ \\
\hline $\mathrm{MCA}\left(\mathrm{MOC}_{\mathrm{atm}}-\right.$ pre $) \mathrm{PC} 1(\mathrm{MOC})$ & $r=-0.92[-0.96,-0.85] p<0.001$ & $r=-0.16[-0.45,0.16] p=0.33$ & & $41 \%$ \\
\hline $\mathrm{MCA}\left(\mathrm{MOC}_{\mathrm{atm}}-\right.$ pre $) \mathrm{PC} 1($ pre $)$ & $r=-0.85[-0.92,-0.85] p<0.001$ & $r=-0.25[-0.52,0.08] p=0.13$ & & $41 \%$ \\
\hline $\mathrm{MCA}\left(\mathrm{MOC}_{\mathrm{atm}}-\right.$ pre $) \mathrm{PC} 2(\mathrm{MOC})$ & $r=-0.18[-0.47,0.14] p=0.26$ & $r=0.72[0.52,0.84] p<0.001$ & & $34 \%$ \\
\hline $\mathrm{MCA}\left(\mathrm{MOC}_{\mathrm{atm}}-\right.$ pre) PC2(pre) & $r=-0.11[-0.41,0.22] p<0.52$ & $r=0.87[0.76,0.93] p<0.001$ & & $34 \%$ \\
\hline $\mathrm{PC} 1{ }^{F_{O}^{\mathrm{IP}}}$ & $r=-0.65[-0.80,-0.43] p<0.001$ & $r=0.004[-0.28,0.35] p=0.82$ & $67 \%$ & \\
\hline $\mathrm{PC} 3^{F_{O}^{\mathrm{IP}}}$ & $r=0.27[-0.05,0.54] p=0.10$ & $r=0.79[0.63,0.88] p<0.001$ & $7 \%$ & \\
\hline $\mathrm{PC} 1^{\text {precip }}$ & $r=-0.82[-0.90,-0.68] p<0.001$ & $r=-0.27[-0.54,0.04] p=0.09$ & $36 \%$ & \\
\hline $\mathrm{PC} 2^{\text {precip }}$ & $r=-0.52[-0.71,-0.25] p<0.001$ & $r=0.50[0.22,0.70] p=0.001$ & $23 \%$ & \\
\hline$F_{O}^{\mathrm{IP}}$ & $\begin{array}{l}r=-0.62[-0.78,-0.38] p<0.001 \\
\quad(r=-0.79[-0.90,-0.56] p<0.001)^{b}\end{array}$ & $r=-0.01[-0.33,0.30] p=0.93$ & & \\
\hline$F_{O}^{\mathrm{IP}}(\mathrm{ECCO})$ & $(r=-0.75[-0.88,-0.49] p<0.001)^{b}$ & $(r=-0.13[-0.50,0.29] p=0.55)^{b}$ & & \\
\hline$F_{O}^{\text {Atl }}$ & $r=0.02[-0.29,-0.34] p=0.88$ & $r=0.09[-0.24,0.39] p=0.60$ & & \\
\hline$F_{A}$ & $\begin{array}{l}r=-0.50[-0.71,-0.22] p=0.001 \\
\quad(r=-0.32[-0.64,-0.10] p<0.013)^{b}\end{array}$ & $r=0.04[-0.35,0.28] p=0.82$ & & \\
\hline$F_{\mathrm{TOA}}$ & $r=-0.42[-0.66,-0.11] p=0.01$ & $r=0.12[-0.22,0.42] p=0.49$ & & \\
\hline$F_{S}^{\mathrm{IP}}$ & $\begin{array}{l}r=-0.35[-0.61,-0.03] p=0.03 \\
\quad(r=-0.66[-0.82,-0.41] p<0.001)^{a} \\
\quad(r=-0.73[-0.87,-0.46] p<0.001)^{b}\end{array}$ & $r=0.13[-0.20,0.45] p=0.45$ & & \\
\hline$F_{S}^{\mathrm{IP}}(\mathrm{ECCO})$ & $(r=-0.36[-0.67,0.05] p=0.08)^{b}$ & $(r=-0.11[-0.49,0.11] p=0.60)^{b}$ & & \\
\hline$\langle[\bar{v}][\overline{\mathrm{MSE}}]\rangle$ & $r=-0.37[-0.62,-0.06] p=0.02$ & $r=0.15[-0.18,0.44] p=0.37$ & & \\
\hline$\left\langle\left[\bar{v}^{*} \overline{\mathrm{MSE}}^{*}\right]\right\rangle$ & $r=-0.14[-0.44,0.18] p=0.39$ & $r=-0.26[-0.53,0.07] p=0.12$ & & \\
\hline$\left\langle\left[\overline{v^{\prime} \mathrm{MSE}^{\prime}}\right]\right\rangle$ & $r=-0.07[-0.37,0.25] p=0.69$ & $r=-0.01[-0.31,0.32] p=0.97$ & & \\
\hline$\langle[\bar{v} \bar{\theta}]\rangle$ & $r=-0.60[-0.77,-0.35] p<0.001$ & $r=0.02[-0.30,0.33] p=0.92$ & & \\
\hline$\left\langle\left[\overline{v^{\prime} \theta^{\prime}}\right]\right\rangle$ & $r=-0.64[-0.80,-0.41] p<0.001$ & $r=0.002[-0.31,0.32] p=0.99$ & & \\
\hline$S_{A}$ & $r=0.11[-0.22,0.40] p=0.52$ & $r=-0.02[-0.35,0.28] p=0.84$ & & \\
\hline NEI & $r=-0.03[-0.34,0.29] p=0.85$ & $r=0.80[0.66,0.89] p \leq 0.001$ & & \\
\hline $\mathrm{SSH}_{S}$ & $(r=0.45[0.07,0.72] p=0.02)^{c}$ & $(r=0.80[0.59,0.91] p \leq 0.001)^{c}$ & & \\
\hline $\mathrm{SSH}_{N}$ & $(r=-0.56[-0.78,-0.21] p=0.004)^{c}$ & $(r=-0.18[-0.53,0.23] p=0.40)^{c}$ & & \\
\hline $\mathrm{SSH}_{S N}$ & $(r=0.12[-0.29,0.49] p=0.57)^{c}$ & $(r=0.69[0.41,0.85] p \leq 0.001)^{c}$ & & \\
\hline $\mathrm{SSH}_{E}$ & $(r=-0.04[-0.43,0.36] p=0.83)^{c}$ & $(r=0.90[0.79,0.96] p \leq 0.001)^{c}$ & & \\
\hline $\mathrm{SSH}_{W}$ & $(r=0.26[-0.16,0.59] p=0.22)^{c}$ & $(r=-0.65[-0.83,-0.34] p \leq 0.001)^{c}$ & & \\
\hline $\mathrm{MSE}_{\text {diff }}$ & $r=0.95[0.90,0.97] p<0.001$ & $r=0.21[-0.12,0.49] p=0.20$ & & \\
\hline SSTa & $r=0.84[0.72,0.92] p<0.001$ & $r=-0.03[-0.34,0.29] p=0.87$ & & \\
\hline
\end{tabular}

expected to result from the weakened zonal thermocline slope in the eastern part of the basin. To get a deepened STC in the warm phase it appears that the poleward geostrophic anomaly must be larger than the equatorward Ekman anomaly. In such a scenario, equatorward geostrophic transport occurring deeper in the water column, which would normally be part of the deep cell, would then be needed to balance the poleward geostrophic anomaly and would hence become a part of the STC. Similarly, in the cold phase, if the then equatorward geostrophic anomaly increases more than the, in that case, poleward Ekman transport anomaly, the STC would become more shallow. This mode is thus consistent with overturning variability driven primarily by changes in the geostrophic transport due to changes in the zonal thermocline slope, although other interpretations are certainly also possible.

The cross-equatorial oscillation appears as stronger than that related to ENSO in this analysis, while 


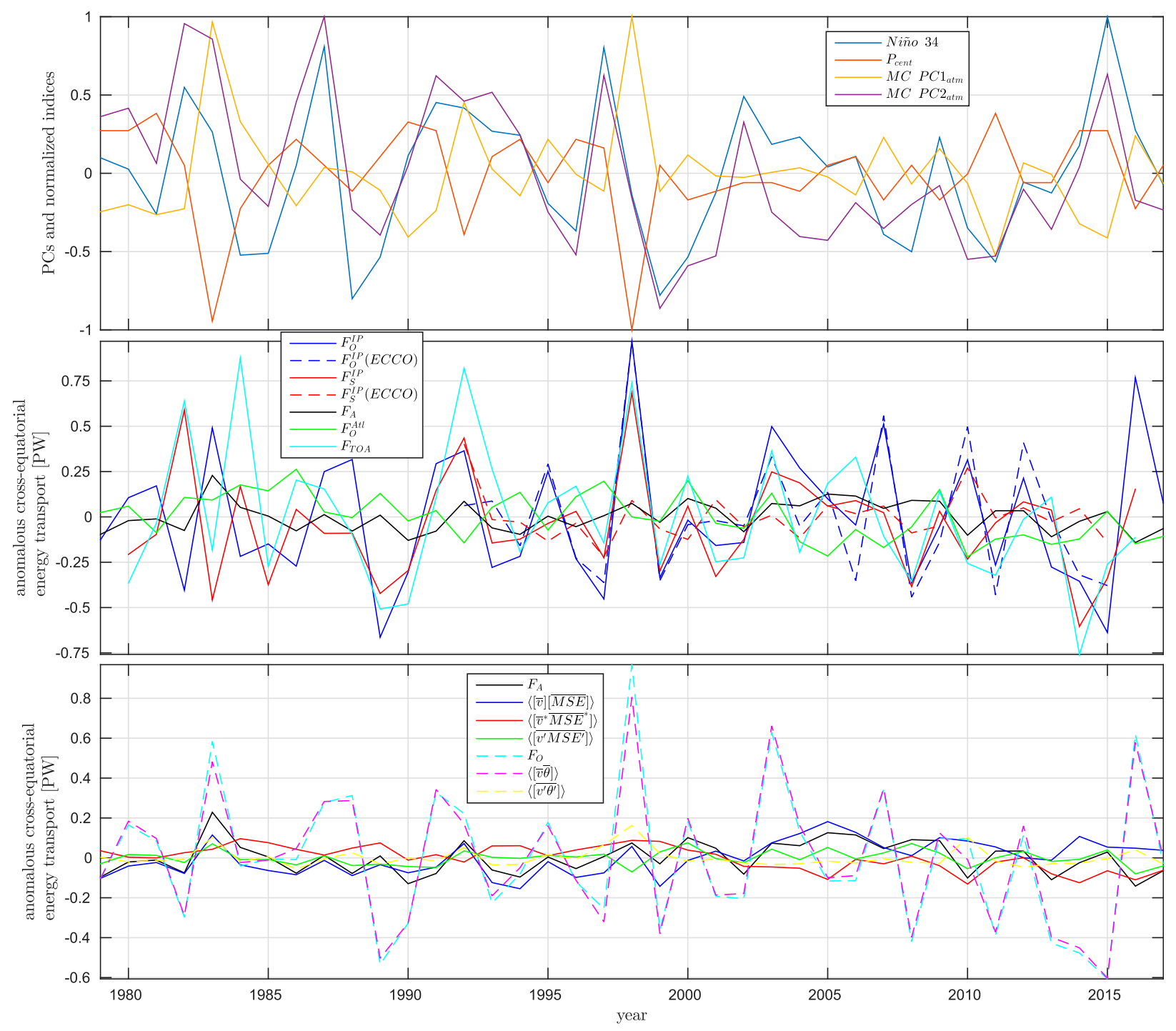

FIG. 3. (middle),(bottom) Anomalous (i.e., means are removed) yearly averaged cross-equatorial energy transports in the atmosphere, the Atlantic Ocean, the Indo-Pacific Ocean, the ocean surface fluxes in the Northern Hemisphere Indo-Pacific, and the net energy flux at the top of the atmosphere integrated over the Northern Hemisphere and (top) normalized PCs and $P_{\text {cent }}$ and Niño-3.4 indices. $F_{O}^{\mathrm{IP}}$ is the cross-equatorial energy transport in the Indo-Pacific Ocean, $F_{S}^{\mathrm{IP}}$ is the energy flux at the ocean surface in the Indo-Pacific integrated north of the equator, $F_{A}$ is the cross-equatorial energy transport in the atmosphere, $F_{O}^{\mathrm{Atl}}$ is the cross-equatorial energy transport in the Atlantic Ocean, $F_{\mathrm{TOA}}$ is the net energy flux at the top of the atmosphere integrated over the Northern Hemisphere, and $\mathrm{MCPC} 1_{\mathrm{atm}}$ and $\mathrm{MCPC} 2_{\mathrm{atm}}$ are the first and second principal components of the MCA of the atmosphere and ocean overturning. The eddy-mean flow decompositions are defined in section $2 b$.

ENSO-related interannual variability tend to dominate the interannual variability of many important climate metrics. One reason for this is that we focus on the meridional overturning and meridional fluxes here, while ENSO is predominantly a zonal oscillation. The two modes are uncorrelated at zero lag but are significantly correlated with a 1 -yr lag, as seen in Fig. 4. The figure shows that a year with a warm Niño-3.4 region is typically preceded by a year with an anomalously northward ITCZ position, and succeeded by one with an anomalously southward ITCZ position.

Another reason for the dominance of the cross-equatorial oscillation over ENSO is the usage of means over calendar years. As an alternative we also did an MCA analysis of the overturning on years starting in July and ending in June shown in appendix A. In this case, the Niño-3.4 index and $P_{\text {cent }}$ are correlated at zero lag, and the first MC mode is correlated to both indices. One possibility is that the heating cycle inherent to ENSO is asymmetric enough around the 


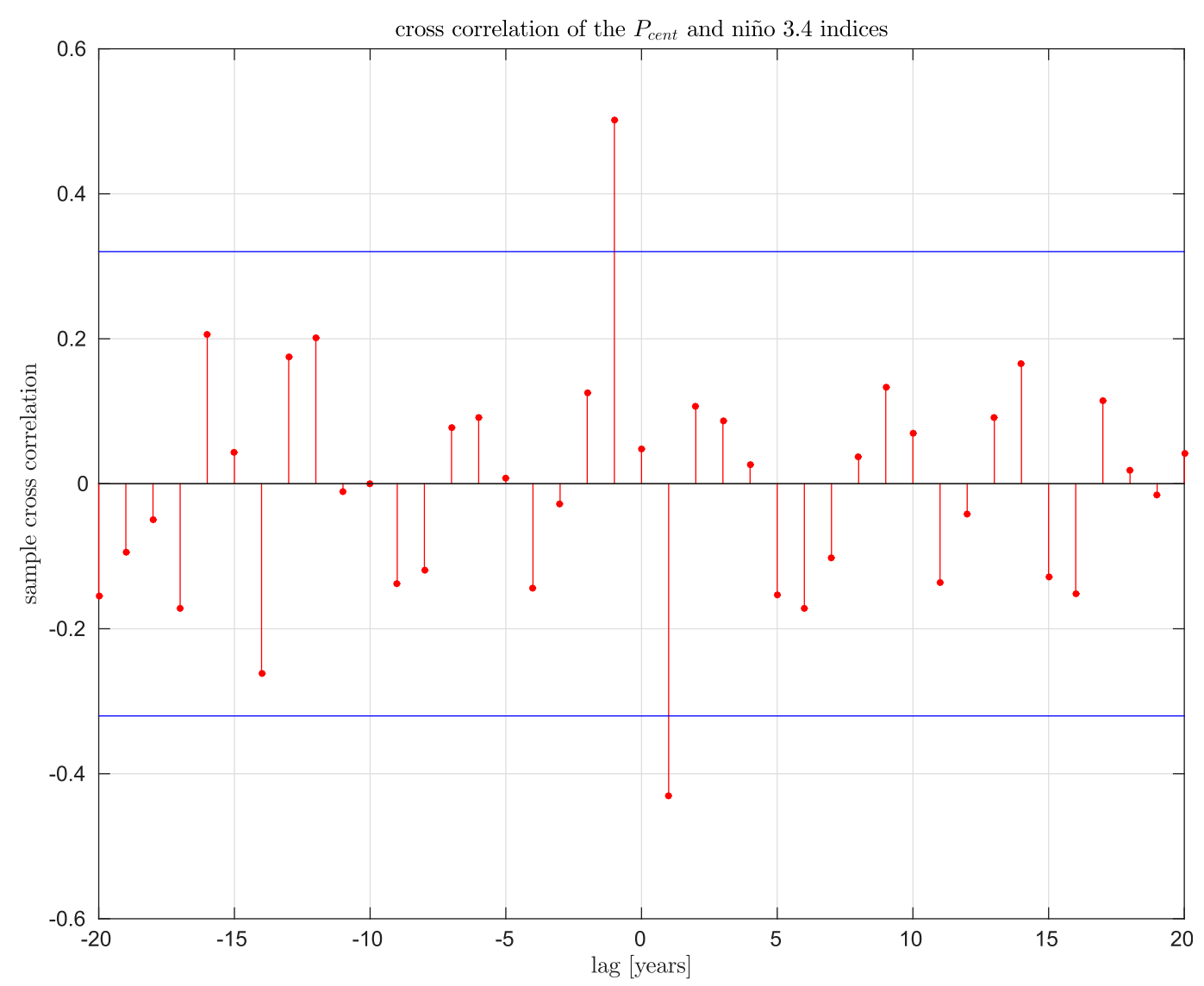

FIG. 4. Cross correlations between the Niño-3.4 and the $P_{\text {cent }}$ index. Negative lags show $P_{\text {cent }}$ leading Niño-3.4 and vice versa. The blue lines are $95 \%$ confidence bounds.

equator to trigger the cross-equatorial oscillation, much like ITCZ migrations are triggered by imposed radiative imbalances in many recent studies (Green and Marshall 2017; Hawcroft et al. 2018; Xiang et al. 2018; Yu and Pritchard 2019). If that is generally the case, then the cross-equatorial oscillation is perhaps best regarded as an underappreciated meridional aspect of the ENSO phenomenon, and the first and second mode could then be seen as the same mode but in different phases. However, both the moderate strength of the cross correlation between $P_{\text {cent }}$ and the Niño-3.4 index using both definitions of year, and the fact that a response very similar to the first mode is triggered by radiative perturbations without triggering ENSO like variability in many recent publication, suggest that that might be an overinterpretation.

The same diagnostics used here on the Indo-Pacific overturning have also been applied to the Atlantic Ocean. However, we found no evidence of interesting coupled atmosphere-ocean overturning variability in our analysis of the Atlantic overturning. We therefore opted to give only a short description of those results, which is found in appendix B.

\section{b. Energy fluxes}

It is generally accepted that the ITCZ typically resides in the hemisphere most strongly heated by top of the atmosphere and surface energy fluxes, and that the sign of $F_{A}$ is such that it transports energy away from that hemisphere (Frierson et al. 2013; Marshall et al. 2014; Green and Marshall 2017). The connection is most easily understood by considering the energy budget for the atmosphere in the Northern Hemisphere,

$$
\frac{d E_{A}}{d t}=F_{S}+F_{A}-F_{\mathrm{TOA}}
$$

where $E_{A}$ is the integrated energy content of the atmosphere north of the equator, $F_{S}$ is the upward surface heat flux integrated over the Northern Hemisphere, $F_{A}$ is, as before, the atmospheric cross-equatorial energy transport, and $F_{\mathrm{TOA}}$ is the upward energy flux at the top of the atmosphere integrated over the Northern Hemisphere. The time rate of change of $E_{A}$ is typically small on interannual time scales, which implies that $F_{\mathrm{TOA}} \approx$ $F_{A}+F_{S}$. The ocean may also play a role in this drama through the term $F_{S}$, which is equal in magnitude and of 
the same sign as $F_{O}$ if there is no energy storage in the ocean. Moreover, $F_{O}$ and $F_{A}$ are constrained to have the same sign for a circulation such as the cross-equatorial oscillation shown in Fig. 2, since both cells have energy densities that increase with height. A consequence of the couplings between $F_{O}$ and $F_{A}$ and between $F_{O}$ and $F_{S}$ is that oceanic energy transport can damp ITCZ migrations. This was shown by Green and Marshall (2017) where they compared the response to hemispheric albedo perturbations in an atmosphere-slab ocean model to those in a fully coupled model. ${ }^{1}$

The ITCZ position can also be related to the energy budget using the energy flux equator framework (Kang et al. 2008; Bischoff and Schneider 2014, 2016; Kang et al. 2018). This is done by Taylor expanding the atmospheric meridional energy transport, $F_{A}(y)$, around the equator; to first order we get

$$
F_{A}(y)=F_{A}(0)+\frac{\partial F_{A}}{\partial y} y
$$

where $F_{A}(0)$ is the atmospheric cross-equatorial energy transport, which we also call $F_{A}$ when no $y$ dependence is considered. Assuming that the energy flux equator [the latitude where $F_{A}(y)=0$ ] coincides with the ITCZ position, its position is given by

$$
y=-\frac{F_{A}(0)}{\frac{\partial F_{A}}{\partial y}} \approx-\frac{F_{A}(0)}{F_{S}(0)-F_{\mathrm{TOA}}(0)}
$$

where $F_{S}(0)$ and $F_{\mathrm{TOA}}(0)$ are the fluxes at the equator, not the integrated ones used in Eq. $(8), F_{S}(0)-F_{\text {TOA }}(0)$ is the so-called net energy input at the equator (NEI), and the approximation is derived assuming there is no change in the atmospheric energy content (Bischoff and Schneider 2014).

The cross-equatorial energy transport anomalies calculated from our reanalysis products are shown in Fig. 3. Just as in Donohoe et al. (2014), we find the energy transport in the Atlantic Ocean $\left(F_{O}^{\mathrm{Atl}}\right)$ to be uncorrelated to $P_{\text {cent }}$. However, we find the Indo-Pacific crossequatorial energy transport $\left(F_{O}^{\mathrm{IP}}\right)$ to be more strongly anticorrelated to $P_{\text {cent }}$ than its atmospheric counterpart, having $r=-0.62$ compared to $r=-0.50$ for the ORAS4 and ERA-Interim estimates, and $r=-0.75$ compared to $r=-0.32$ for the ECCO-V4r3 and ERA-Interim estimates over the $1992-2015$ period. $F_{\text {TOA }}$ is here calculated from the approximate budget $F_{\mathrm{TOA}} \approx F_{A}+F_{S}$. It has a standard deviation of $0.37 \mathrm{PW}$, and it is seen to

\footnotetext{
${ }^{1}$ A model where lateral ocean energy fluxes are prescribed.
}

rather closely match the surface fluxes in the IndoPacific Ocean $\left(F_{S}^{\mathrm{IP}}\right)$.

Moreover, the interannual variability in the crossequatorial energy transport, shown in Fig. 3, is dominated by the Indo-Pacific Ocean, which has a standard deviation of $0.37 \mathrm{PW}$ (0.36 PW in ECCO-V4r3) compared to $0.13 \mathrm{PW}$ for the Atlantic Ocean and 0.083 PW for the atmosphere (0.073 PW over the time span of the ECCO-V4r3 estimate). The larger oceanic than atmospheric energy transport variability does not necessarily imply a larger $F_{S}$ than $F_{A}$, since $\left(d E_{O} / d t\right)$ [see Eq. (5)] is sizable on interannual time scales having a standard deviation of $0.35 \mathrm{PW}$. We therefore quantify the covariance of oceanic surface energy fluxes in the IndoPacific Ocean, $F_{S}^{\mathrm{IP}}$, with $P_{\text {cent }} F_{S}^{\mathrm{IP}}$, also shown in Fig. 3 , has a standard deviation of 0.28 (0.13) PW in ORAS4 (ECCO-V4r3) and a correlation with $P_{\text {cent }}$ of $r=-0.35$ $(r=-0.36)$. The weaker anticorrelation between $F_{S}^{\mathrm{IP}}$ and $P_{\text {cent }}$ than between $F_{A}$ and $P_{\text {cent }}$ in the ORAS4 reanalysis is, however, entirely due to the first five years of the reanalysis data; excluding those years gives $r=-0.66$. Moreover, over the time span of the ECCOV4r3 estimate the anticorrelation between $F_{S}^{\mathrm{IP}}$ from ECCO-V4r3 and $P_{\text {cent }}$ is also stronger than that between $F_{A}$ and $P_{\text {cent }}$ having $r=-0.36$ compared to $r=-0.32$. Our analysis thus shows that the interannual variability of the Indo-Pacific cross-equatorial energy transport is both larger and more strongly anticorrelated with $P_{\text {cent }}$ than its atmospheric counterpart in both reanalyses. Moreover, we find the same to be true of the IndoPacific surface fluxes in both reanalyses. Both findings suggest a considerable damping of ITCZ migrations on interannual time scales owing to Indo-Pacific energy transport. The much smaller and uncorrelated Atlantic energy transport, meanwhile, suggests that the Atlantic Ocean has little to do with this mode of interannual variability.

$F_{A}$ can be split into constituents from latent heat, sensible heat, and geopotential transports, and all these three transports are tightly coupled to the ITZC position and are thus very strongly correlated to $P_{\text {cent }}$, each having $|r| \geq 0.92$. More interestingly, they are even more strongly correlated to the PCs of the first atmospheric overturning mode all having $|r| \geq 0.96$. Overturning variations are thus strongly correlated to the individual constituents of $F_{A}$ but only moderately correlated to $F_{A}$. How can this be? Held (2001) related $F_{A}$ to the strength of the overturning circulation $V$ and the gross atmospheric stability (i.e., the energy difference between the northward and southward flowing branch of the overturning circulation), $S_{A}$, through $F_{A}=-V S_{A}$. The negative sign here ensures consistency with Fig. 1 where a clockwise circulation is negative. Since we 
know that each constituent of $F_{A}$ is strongly correlated to $V$, it seems that interannual variations in $S_{A}$ must be causing the weaker correlations between $F_{A}$ and $P_{\text {cent }}$ than between the constituents of $F_{A}$ and $P_{\text {cent }}$. Moreover, $F_{A}$ is a small residual of opposing contribution from on the one hand latent and sensible heat transport and on the other geopotential transport, both of which are an order of magnitude larger than $F_{A}$. Even small variations in $S_{A}$ can thus give considerable contributions to $F_{A}$.

Taking the PCs of the first atmospheric overturning mode as a proxy for $V$, we can estimate $S_{A}$ from $S_{A} \approx F_{A} / V$. Estimated this way, $S_{A}$ is uncorrelated to both to the Niño-3.4 index and to $P_{\text {cent }}$. One could also suspect that $S_{A}$ should depend on $\partial F_{A} / \partial y$ or equivalently on the NEI [see Eq. (10)], however, these are also uncorrelated. Moreover, NEI is found to be strongly correlated to the Niño-3.4 index and uncorrelated to $P_{\text {cent }}$, which indicates that energy transport variations rather than variations in the equatorial energy flux divergence drive the interannual variability in $P_{\text {cent }}$, see Eq. (10). The strong correlation between the Niño-3.4 index and NEI is consistent with the findings of Adam et al. (2016), while the correlation between $F_{A}$ and $P_{\text {cent }}$ is much stronger in our work and in that of Donohoe et al. (2014) than in that of Adam et al. (2016), as was discussed in the introduction. The reason behind this discrepancy is that we use the improved MSE formulation of Mayer et al. (2017). Using the older MSE formulation we also we also find $F_{A}$ to be uncorrelated to $P_{\text {cent }}$ on interannual time scales, while the correlation between $F_{A}$ computed with the new and old formulation is $r=0.76$. The fact that seemingly small methodological differences can give such diverging results highlights that considerable uncertainty still persists in our estimates of $F_{A}$.

A decomposition of $F_{A}$ and $F_{O}$ into mean and eddy components is shown in the lower panel of Fig. 3. The mean components are dominating the interannual variability both for $F_{A}$ and $F_{O}$; however, the dominance is much stronger for $F_{O}$. The standard deviations of the atmospheric parts are $0.082 \mathrm{PW}$ for the mean meridional part, $0.061 \mathrm{PW}$ for the stationary eddy part, and 0.038 PW for the transient eddy part. The oceanic mean part has a standard deviation $0.33 \mathrm{PW}$, while that for the transient eddy part is $0.045 \mathrm{PW}$. The anticorrelation between $P_{\text {cent }}$ and $F_{A}$ is mostly owing to the mean meridional circulation, which has $r=-0.37$ with $P_{\text {cent }}$. Both the stationary and transient eddy parts are very weakly anticorrelated with $P_{\text {cent }}$. However, the sum of the stationary eddy and mean meridional circulation parts has $r=-0.66$ with $P_{\text {cent }}$. The sum of these two terms is what makes up the mean term in the $F_{O}$ decomposition, which has $r=-0.60$ with $P_{\text {cent }}$. Thus, the anticorrelation between $F_{O}$ and $P_{\text {cent }}$ is stronger than that between $F_{A}$ and $P_{\text {cent }}$ because the transient eddy term is closer in magnitude to the mean term in the atmosphere than in the ocean, and because the atmospheric transient eddy term in contrast to the oceanic is uncorrelated to $P_{\text {cent }}$. The oceanic transient eddy term is in fact about as strongly correlated to $P_{\text {cent }}$ as the mean term, and it is thus also likely related to temporal variations in the MOC. The atmospheric transient eddy variability meanwhile appears to be unrelated to both coupled modes discussed here. Last, the $F_{A}$ part due to the mean meridional circulation is sometimes used to define an alternative gross atmospheric stability according to $S_{A}^{\text {mean }}=\langle[\bar{v}][\overline{\mathrm{MSE}}]\rangle / V$. We found $S_{A}^{\text {mean }}$ just like $S_{A}$ to be uncorrelated to the climate indices used in this study.

\section{c. Sea level variability}

The significant difference in magnitude of $F_{S}^{\mathrm{IP}}$ between ORAS4 and ECCO-V4r3, and lack thereof for $F_{O}^{\mathrm{IP}}$, suggests that these two estimates have significantly different ocean energy storages; see Eq. (5). Energy in the ocean is stored predominantly as heat, which gives rise to a thermosteric sea level signal. Following Griffies and Greatbatch (2012) we calculate the thermosteric sea level rise as

$$
\Delta \eta=\frac{V}{A} \alpha_{\mathrm{eff}} \Delta T
$$

where $\Delta \eta$ is the thermosteric sea level rise, $V$ is the volume of the water that is being heated, $A$ is its surface area, $\alpha_{\text {eff }}$ is the effective thermal expansion coefficient, and $\Delta T$ is the change in potential temperature. $\alpha_{\text {eff }}$ depends on salinity, temperature, and pressure, but here we will simply assume a salinity of 35 psu and temperature of $10^{\circ} \mathrm{C}$ and a pressure of $500 \mathrm{~dB}$, giving $\alpha_{\text {eff }}=$ $1.76 \times 10^{-4} \mathrm{~K}^{-1}$. We estimate $\Delta T$ from a simplified energy budget where we assume that all interannual variability in $F_{O}^{\mathrm{IP}}$ is used to heat the ocean, giving

$$
\rho_{0} c_{p} V \Delta T=F_{O}^{\mathrm{IP}} \Delta t
$$

where $\Delta t$ is one year. Equations (11) and (12) give

$$
\Delta \eta=\frac{\alpha_{\mathrm{eff}} F_{O}^{\mathrm{IP}} \Delta t}{A \rho_{0} c_{p}} .
$$

To calculate $\Delta \eta$ from Eq. (13) we use an area, $A$, taken to be the Indo-Pacific between latitudes $0^{\circ}$ and $15^{\circ} \mathrm{N}$, which corresponds roughly to the extent of the streamfunction anomaly owing to cross-equatorial oscillation, and we use the yearly averaged values of $F_{O}^{\mathrm{IP}}$. The standard deviation of the thermosteric variability implied by Eq. (13) is then $0.0126 \mathrm{~m}$. This can be compared 
to the yearly averaged observed sea level anomaly, which is taken from the SSALTO/DUACS all-satellitemerged product $\left(\mathrm{SSH}_{N}\right.$ in Table 1$)$. We recognize that this comparison neglects both sea level variability due to salinity and ocean mass changes. However, away from the coast in the tropics both these effects are negligible on interannual time scales (Vinogradova et al. 2007;

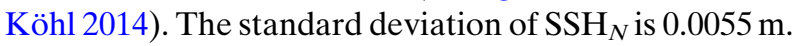
The observed sea level variability is thus only about $44 \%$ of that implied by the thermosteric calculation, where $F_{O}^{\mathrm{IP}}$ was assumed to be stored in its entirety in the ocean. This suggests that a large part of $F_{O}^{\mathrm{IP}}$, something like $56 \%$, in fact, goes into $F_{S}^{\mathrm{IP}}$, and that the remaining $44 \%$ goes into heating the ocean. That is, it suggests a considerable oceanic damping of ITCZ migrations on interannual time scales. This way of estimating $F_{S}^{\mathrm{IP}}$ gives a value that is roughly halfway between those in ORAS4 and ECCO-V4r3.

The sea level variability owing to the cross-equatorial oscillation is a sizable part of the overall interannual Indo-Pacific sea level variability. To illustrate this, we computed annual averages of the sea level anomaly in different parts of the Indo-Pacific Ocean. $\mathrm{SSH}_{S}$ is defined as $\mathrm{SSH}_{N}$ but for the latitudes between $15^{\circ} \mathrm{S}$ and $0^{\circ}$. $\mathrm{SSH}_{S N}$ is the average over the joint domain of $\mathrm{SSH}_{N}$ and $\mathrm{SSH}_{S}$. Last, we defined $\mathrm{SSH}_{E}$ as the eastern part of the Pacific Ocean between $15^{\circ} \mathrm{S}$ and $15^{\circ} \mathrm{N}$ and $\mathrm{SSH}_{W}$ as its western equivalent. The split between $\mathrm{SSH}_{E}$ and $\mathrm{SSH}_{W}$ is at latitude $155^{\circ} \mathrm{W}$. The interannual variability quantified as the standard deviation is largest in $\mathrm{SSH}_{E}=$ 0.0287 followed by $\mathrm{SSH}_{W}=0.0229, \mathrm{SSH}_{S}=0.0085$, $\mathrm{SSH}_{N}=0.0055$, and $\mathrm{SSH}_{S N}=0.0037$ all values are in meters. Since ENSO is mostly a zonal oscillation and the cross-equatorial oscillation is mostly meridional one may expect $P_{\text {cent }}$ to be most strongly correlated to $\mathrm{SSH}_{N}$ and $\mathrm{SSH}_{S}$, and the Niño-3.4 index to be most strongly correlated to $\mathrm{SSH}_{E}$ and $\mathrm{SSH}_{W}$. However, ENSO is also a leading-order contributor to the interannual variability in the globally averaged sea level (Nerem et al. 1999). ENSO-related sea level variability should thus be expected to be larger than that related to the crossequatorial oscillation and can be expected to influence not only $\mathrm{SSH}_{E}$ and $\mathrm{SSH}_{W}$ but also $\mathrm{SSH}_{N}$ and $\mathrm{SSH}_{S}$. Table 1 shows the correlations, and it is clear that $\mathrm{SSH}_{N}$ $\left(\mathrm{SSH}_{S}\right)$ is anticorrelated (correlated) with $P_{\text {cent }}$ as can be expected from the ocean energy transport. Moreover, the correlations between $\mathrm{SSH}_{E}, \mathrm{SSH}_{W}$ and the Niño-3.4 index are also consistent with expectations. The correlation between $\mathrm{SSH}_{S N}$ and the Niño-3.4 index is due to the heat content in the whole tropical Pacific being larger in the warm phase of ENSO (Wyrtki 1985; Jin 1997; Meinen and McPhaden 2000). The correlations between the Niño-3.4 index and $\mathrm{SSH}_{S}$ and $\mathrm{SSH}_{N}$ are

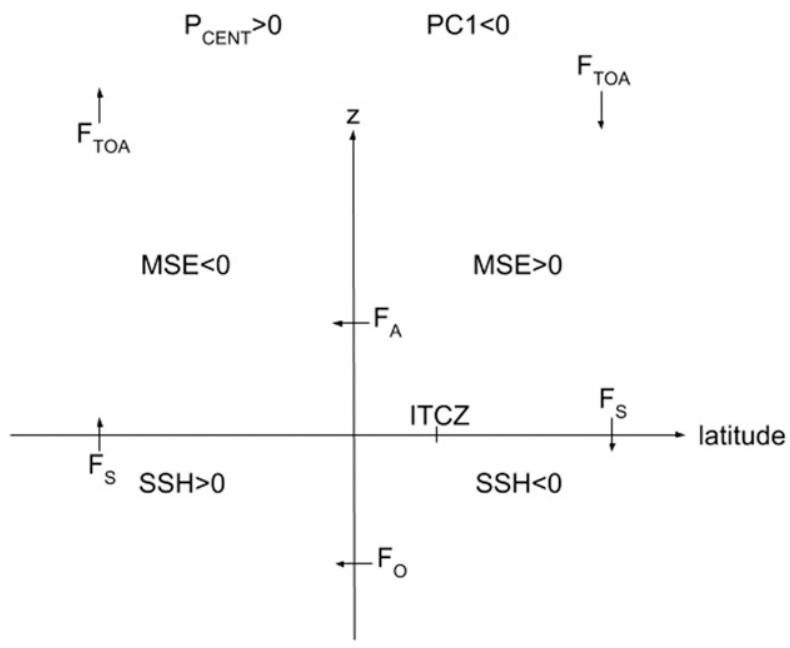

FIG. 5. Schematic of anomalous (i.e., means are removed) energy fluxes and the anomalous energy distribution that are coincident with the PC of the first overturning mode being less than zero, and the ITCZ location being anomalously northward. The $x$ axis separates the ocean from the atmosphere in the sketch. MSE is the anomalous moist static energy, $\mathrm{SSH}$ is the anomalous sea surface height, $F_{\mathrm{TOA}}$ is the anomalous net radiation at the top of the atmosphere, $F_{O}$ is the anomalous cross-equatorial energy transport in the ocean, $F_{A}$ is the anomalous cross-equatorial energy transport in the atmosphere, and $F_{S}$ is the anomalous energy flux at the ocean-atmosphere interface.

harder to understand as both these regions are influenced by opposing sea level contributions from the ENSO related east-west sea level gradient and are thus sensitive to the meridional extent of the eastern cold tongue and western warm pool in the respective hemispheres. Judging by the sign of the correlation, it appears that $\mathrm{SSH}_{S}$ reflects mostly the cold tongue and vice versa.

\section{d. Mechanism}

To pin down the physical mechanisms at work in the cross-equatorial oscillation is not entirely possible from reanalysis data, and would require careful analysis of various coupled and uncoupled climate model integrations. Here we will settle for briefly sketching out the dynamics as we understand them.

We imagine our first overturning mode to be a response to an asymmetry in the atmospheric energy distribution across the equator. The lagged correlations between $P_{\text {cent }}$ and the Niño-3.4 index shown in Fig. 4 suggest that the ENSO heating cycle might be one way of setting up such an asymmetry, but there are many possibilities. Figure 5 shows a sketch of the anomalous energy fluxes and the anomalous energy distribution that are coincident with an excessively northward ITCZ position (Donohoe et al. 2014; Schneider et al. 2014; Kang et al. 2018). $P_{\text {cent }}$ correlates strongly with the 
difference in moist static energy content between the two hemispheres. We define the quantity $\mathrm{MSE}_{\text {diff }}$ as the moist static energy integrated between latitudes $0^{\circ}$ and $15^{\circ}$ in the Northern Hemisphere minus that integrated over the same latitude band in the Southern Hemisphere, and it has $r=0.95$ with $P_{\text {cent }}$. The annual average ITCZ position is thus shifted north, when the energy content of the tropical Northern Hemisphere is large compared to that in the southern one, as is shown in Fig. 5.

The correlations between $P_{\text {cent }}$ and $\mathrm{SSH}_{N}$ and $\mathrm{SSH}_{S}$ both suggest that the opposite is true of the energy content in the tropical ocean. That is, an anomalously northward ITCZ position is associated with an anomalously low (high) energy content in the north (south) Indo-Pacific Ocean, and with an oceanic energy transport from the Northern Hemisphere to the southern (i.e., an energy transport from low to high energy content). The ocean energy transport can thus not be driven by the oceanic hemispheric energy contrast through, for example, baroclinic instability, rather we believe it to be wind driven as in Green and Marshall (2017) and Kang et al. (2018). The standard deviation of $\mathrm{MSE}_{\mathrm{diff}}$ is smaller than that of $\left(F_{A}+F_{S}\right) \Delta t$ by a factor of 3 to 5 depending on whether we use the ORAS4 or the ECCOV4r3 estimate, suggesting that the left-hand side of Eq. (8) can be neglected when the budget is averaged over a year, which is also consistent with (Fasullo and Trenberth 2008). Thus, the hemisphere with the MSE deficit must lose energy at the top of the atmosphere, and vice versa, to sustain the hemispheric MSE content contrast during the phases of the mode. This might work analogously to the Hadley circulation where radiative cooling is enhanced by cloud radiative effects in the descending branch (Loeb et al. 2014). The cloud climatology is distinctly different in the ascending and descending branch of the Hadley circulation, and cooling stratocumulus clouds frequently occur in the descending branch (Klein and Hartmann 1993; Bender et al. 2017).

What to consider as forcing in this oscillation is somewhat ambiguous owing to the coupled nature of the phenomenon. However, Liu et al. (2018) found using a simplistic energy balance model that perturbing surface energy fluxes tended to give $F_{A}$ and $F_{O}$ perturbations of opposite signs, while perturbations in $F_{\mathrm{TOA}}$ tended to give $F_{A}$ and $F_{O}$ perturbations of the same sign, which gives some support for considering the $F_{\mathrm{TOA}}$ fluxes as a forcing. However, the fact the hemispheric energy gradients in the atmosphere and ocean have opposite signs owing to the larger $F_{O}$ than $F_{S}$ opens up the possibility of having a self-sustained oscillation. That is, when the ITCZ shifts northward in response to an energy excess in the Northern Hemisphere atmosphere and $F_{A}$ and $F_{O}$ become southward, $F_{O}$ does in part contribute to diminish the atmospheric energy contrast through its contribution to $F_{S}$, but it also contributes to energy storage and sea level rise in the tropical Southern Hemisphere ocean. The greater oceanic than atmospheric energy transport suggests that when the hemispheric energy contrast in the atmosphere has been eroded, there is instead an oceanic energy contrast present in the tropics, with greater energy content in the Southern Hemisphere. If this excess heat now found in the tropical Southern Hemisphere ocean is exchanged with the atmosphere it could set up a hemispheric energy contrast in the atmosphere of opposite sign to the one we started with and force the ITCZ south and restart the oscillation. Moreover, the oceanic energy transport goes from the hemisphere where the SST is warm (see section $3 \mathrm{f}$ below) to that where it is cold. The SST will thus gradually increase in the hemisphere where the atmosphere has an anomalously low energy content, and may ultimately hinder the formation of cooling low clouds and thereby affect $F_{\mathrm{TOA}}$ and constrain the period of the oscillation.

\section{e. Damping of ITCZ migrations}

Green and Marshall (2017) found that ITCZ migrations due to an imposed radiation asymmetry between the hemispheres were damped by about a factor of 4 when their atmospheric model was coupled to an ocean model instead of a slab ocean model. Using theory and observations Schneider (2017) calculated a damping factor of 3 for our present climate, here we will do similar calculations, but our focus is more directly on the interannual time scales than in those works. Figure 6 shows scatterplots of cross-equatorial energy fluxes against ITCZ migrations and their respective regression coefficients. We find a regression coefficient of $-2.17^{\circ} \pm$ $2.84^{\circ} \mathrm{PW}^{-1}$ for $F_{A}$, which is quite similar to the $-1.6^{\circ} \pm$ $0.7^{\circ} \mathrm{PW}^{-1}$ coefficient found by Donohoe et al. (2014), although with a much larger $95 \%$ confidence interval. The two regressions of $F_{S}^{\mathrm{IP}}$ from ORAS4 and ECCOV4r3 also give estimates that are consistent with each other.

If $F_{S}^{\mathrm{IP}}$ and $F_{A}$ were both linear functions of $P_{\text {cent }}$ alone, then the regressions shown in Figs. $6 \mathrm{a}$ and $6 \mathrm{~b}$ could be used to calculate the ITCZ migration that would result in a hemispheric heating anomaly from $F_{A}$ and $F_{S}$ of $1 \mathrm{PW}$. The resulting equation is

$$
F_{A}+F_{S}=1=\frac{\Delta \mathrm{ITCZ}}{2.17}+\frac{\Delta \mathrm{ITCZ}}{1.31}
$$

giving $\triangle \mathrm{ITCZ}=0.82^{\circ}$, and using the regression from the ECCO-V4r3 estimate would give a similar number. The damping factor in this idealized case would thus be 

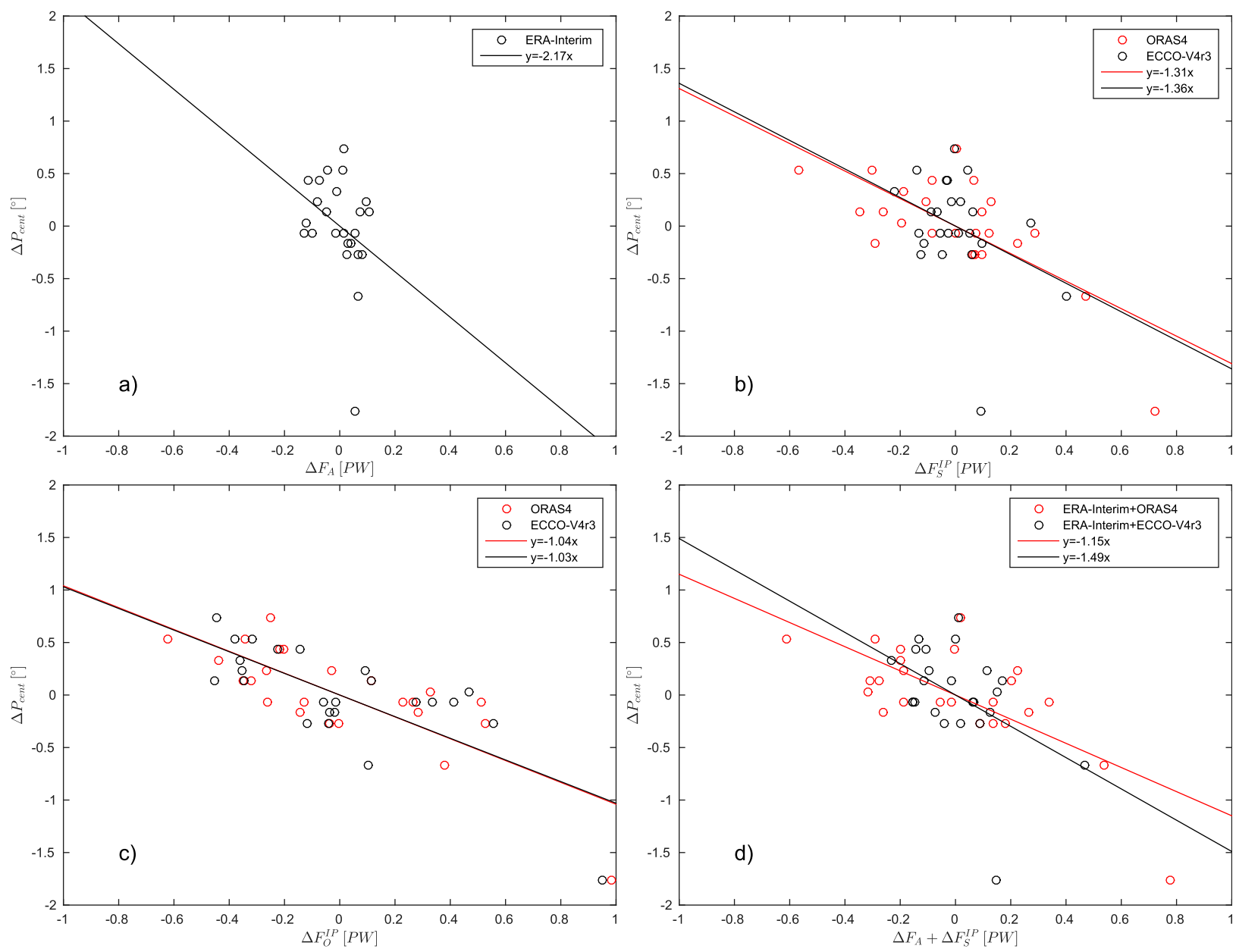

FIG. 6. ITCZ migrations plotted against anomalous (i.e., means are removed) atmospheric cross-equatorial, Indo-Pacific cross-equatorial, and surface energy fluxes, over the time frame of the ECCO-V4r3 state estimate (1992-2015). $P_{\text {cent }}$ is taken from ERA-Interim in all calculations. The $95 \%$ confidence bounds on the regressions are (a) \pm 2.84 , (b) red \pm 0.55 , black \pm 1.54 , (c) red \pm 0.36 , black \pm 0.41 , and (d) red \pm 0.49 , black \pm 1.26 , all in units of ${ }^{\circ} \mathrm{PW}^{-1}$.

$2.17 / 0.82=2.6$. For perturbations on much longer time scales than the interannual one would expect the ocean energy uptake to be small compared to $F_{S}$ in Eq. (5) and thus that $F_{S}$ should be substituted by $F_{O}$ in Eq. (14) in damping calculations on longer time scales. This approach gives a damping factor of 3.1 both for the ORAS4 and the ECCO-V4r3 estimates, in excellent agreement with Schneider (2017). In the real world, however, neither $F_{S}^{\mathrm{IP}}$ nor $F_{A}$ are really linear functions of $P_{\text {cent }}$ on interannual time scales. To quantify the effect of this departure from linearity we quantify the regressions of $F_{S}^{\mathrm{IP}}+F_{A}$ against in $P_{\text {cent }}$ Fig. 6d. Using those regressions give damping factors of 1.9 and 1.5 for the respective estimates.

The real damping factor for the interannual case is thus somewhat uncertain owing both to uncertainties in the estimates of the fluxes and the assumption of their simple functional form. The first caveat here is rather obvious, but for the second it is worth noting that $F_{S}^{\mathrm{IP}}$ and $F_{A}$ are not necessarily independent of each other. That is, the regression coefficient for $F_{A}$ could possibly be different in the absence of ocean heat transport. Our estimated damping coefficients are thus not necessarily directly comparable to those Green and Marshall (2017), where a slab ocean model is compared to a coupled model. Regardless of these caveats, our analysis clearly suggests that the ocean circulation in the Indo-Pacific imposes a considerable damping on interannual ITCZ migrations.

\section{f. Precipitation and SST patterns}

The important role the Indo-Pacific Ocean plays for the precipitation patterns in the tropics is also indicated by the first two MC modes of the atmospheric MOC and 

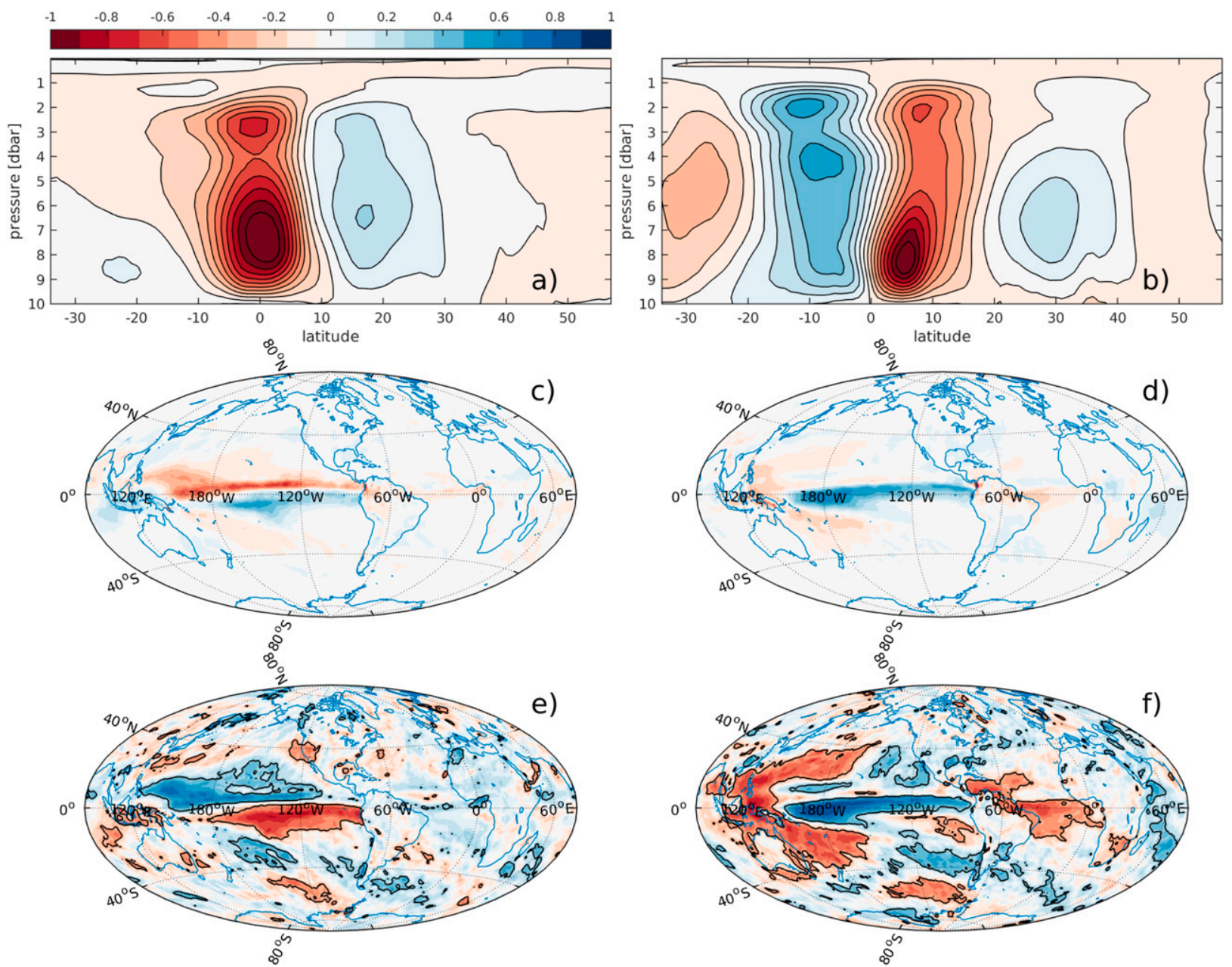

FIG. 7. (a),(c) First MC modes of the atmospheric overturning and yearly averaged precipitation, and (b),(d) second MC modes of the atmospheric overturning and yearly averaged precipitation. (e) Spatial map of correlation coefficients between $P_{\text {cent }}$ and the yearly average precipitation and (f) spatial map of correlation coefficients between the Niño-3.4 index and the yearly average precipitation. Black edges around contours in (e) and (f) indicate areas where $p<0.05$.

the global precipitation shown in Figs. 7a-d. The first two modes represent $41 \%$ and $34 \%$, respectively, of the explained squared covariance. The first two MOC modes and their PCs from this MOC-precipitation MCA are very similar to those from the MCA of the atmospheric and oceanic MOCs shown in Fig. 2, indicating that they capture the same patterns of variability. The first MC mode of precipitation reveals the dipole pattern across the equator that one would expect from a migrating ITCZ, but this is only seen in the IndoPacific Ocean, not in the Atlantic. A further indication of the key role of the Indo-Pacific Ocean is seen in Fig. 7e, which shows the correlation between $P_{\text {cent }}$ and the yearly averaged precipitation. Black edges in this panel are drawn around contours where $p<0.05$ and such contours are nearly only present over the IndoPacific Ocean, suggesting again an influence of the
Indo-Pacific Ocean on the precipitation patterns. The second precipitation mode meanwhile shows a good consistency with the precipitation patterns associated with ENSO (Dai and Wigley 2000), which is also seen comparing Figs. $7 \mathrm{~d}$ and $7 \mathrm{f}$.

Figures $8 \mathrm{a}$ and $8 \mathrm{~b}$ show spatial correlations maps between the PCs of the first two atmospheric overturning modes shown in Fig. 2 and the yearly averaged SST. The first mode is significantly correlated with the SST primarily in the Indo-Pacific Ocean, and the mode structure is consistent with an increased SST difference across the equatorial Pacific. This SST asymmetry can be quantified using the SST asymmetry index (SSTa calculated as the difference in mean SST between $0^{\circ}-20^{\circ} \mathrm{N}$ and $20^{\circ} \mathrm{S}-0^{\circ}$ in the Indo-Pacific) (Hawcroft et al. 2018). We found a strong correlation of $r=0.84$ between SSTa and $P_{\text {cent }}$, which is consistent with the findings of 


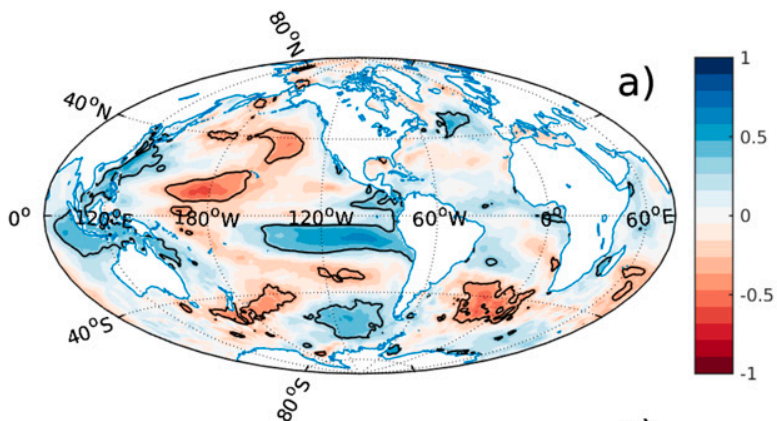

c)

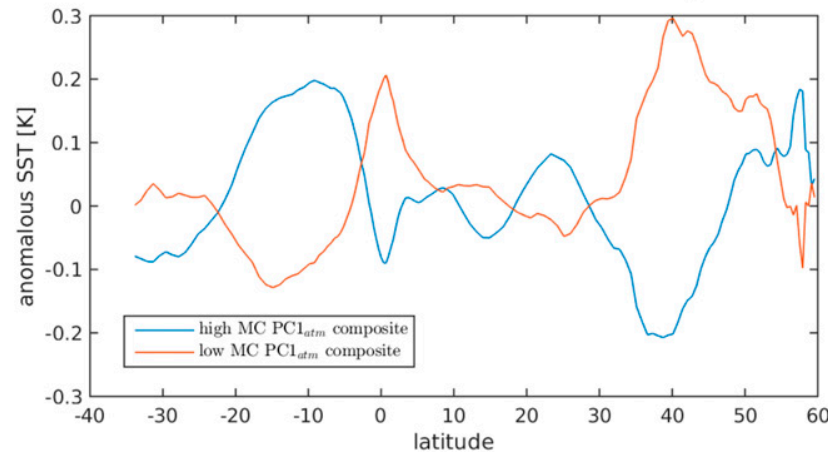

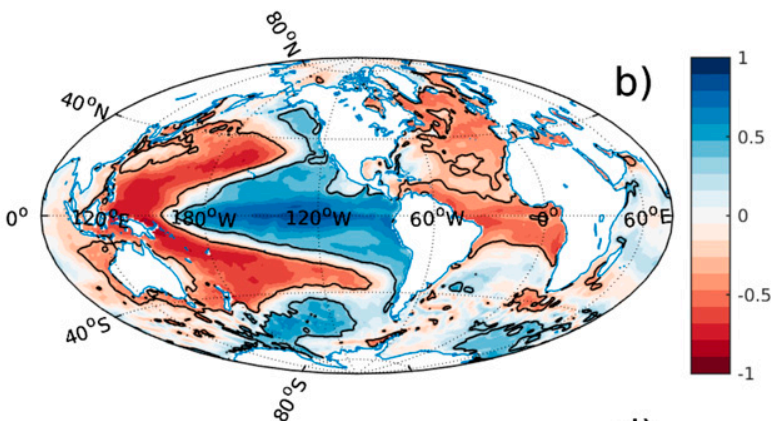

d)

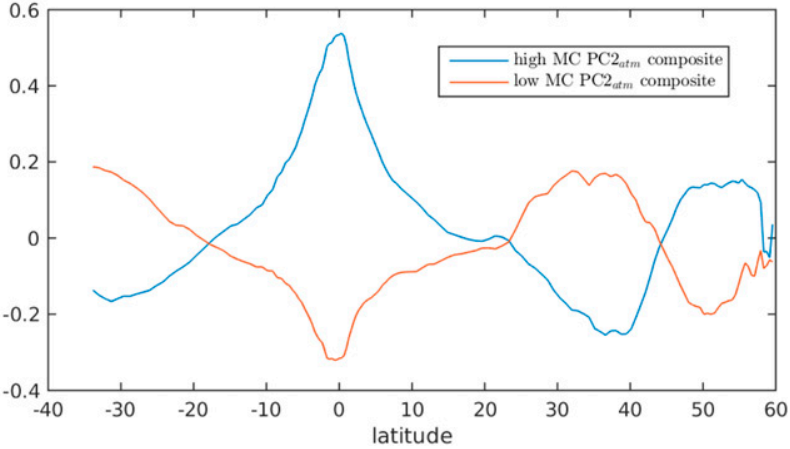

FIG. 8. (a) Spatial map of correlation coefficients between MCPC1 $1_{\mathrm{atm}}$ and the yearly average SST, and (b) spatial map of correlation coefficients between MCPC $2_{\mathrm{atm}}$ and the yearly average SST. (c) Zonally averaged SST anomaly in the Indo-Pacific Ocean averaged over the seven years with the highest and lowest values of $\mathrm{MCPC1}_{\mathrm{atm}}$, and (d) as in (c), but for the seven years with the highest and lowest values of $\mathrm{MCPC} 2_{\mathrm{atm}}$. Black edges around contours in (a) and (b) indicate areas where $p<0.05$.

Hawcroft et al. (2018). The SST pattern owing to the second mode meanwhile is broadly consistent with ENSO variability.

The connection between the ITCZ position and nearequatorial SST gradients is highlighted in some recent publications where ITCZ shifts are imposed by artificial radiation perturbations (Xiang et al. 2018; Hawcroft et al. 2018; Yu and Pritchard 2019), and some contrasting results on the role of these gradients exist. Xiang et al. (2018) found changes in SST gradients to better explain ITCZ migrations than changes in the energy transports, while both Hawcroft et al. (2018) and Yu and Pritchard (2019) found both SST gradients and energy fluxes to change consistently with the ITCZ migrations. SST observations are assimilated by both the oceanic and atmospheric reanalyses, so in a sense they can be considered a part of the forcing in these datasets. In the real world, however, the SST is an emergent property rather than a forcing of the climate system. It is thus hard to see SST patterns as a root cause for the variability described in our first mode. However, SST patterns are certainly a fundamental part of the atmosphere-ocean coupling that directly links ocean dynamics to wind changes and moisture convergence in the boundary layer (Xiang et al. 2018). In an experiment where the latitude band between $20^{\circ} \mathrm{S}$ and $0^{\circ}$ was heated by increased solar radiation, Xiang et al. (2018) found a sharp increase in the SST gradient on the northern and southern ends of the heated area. In Fig. $8 \mathrm{c}$ we can see a very similar anomalous SST pattern in the composites both for the high and low values of MCPC1 $1_{\mathrm{atm}}$. These SST composites are produced by taking a temporal average of the zonally averaged Indo-Pacific SST over the seven years with highest and lowest values of $\mathrm{MCPC}_{\mathrm{atm}}$. Xiang et al. (2018) found this pattern to drive moisture convergence into the heated area from both sides, and to be a primary agent in producing the precipitation changes associated with a low-latitude radiation perturbation. $\mathrm{Yu}$ and Pritchard (2019) did a similar experiment to that of Xiang et al. (2018), but where the latitude band between $15^{\circ} \mathrm{S}$ and $0^{\circ}$ was heated and that between $0^{\circ}$ and $15^{\circ} \mathrm{N}$ was cooled. They found a similar SST pattern to that of Xiang et al. (2018) in the heated part of the domain and a slightly weaker response of opposite sign in the cooled part. This is very similar to the pattern we show in Fig. 8c. Moreover, they found a large SST perturbation, of opposite sign to that found in the southern tropics, centered around $40^{\circ} \mathrm{N}$, which again is very similar to the SST anomaly in our Fig. 8c. The SST changes we see are thus consistent with those seen for low-latitude radiation perturbations, but not with those found for high-latitude perturbations, where 
both Xiang et al. (2018) and Yu and Pritchard (2019) found the SST changes to be more confined to higher latitudes. In conclusion, we find both SST and energy transport changes to be consistent with the ITCZ migrations. This finding is in agreement with Hawcroft et al. (2018); Yu and Pritchard (2019), and there is thus little to suggest from our analysis that either of these two changes is more fundamental than the other for ITCZ migrations. However, the forcing behind the changes in both the energy transport and the SST in Xiang et al. (2018), Hawcroft et al. (2018), and Yu and Pritchard (2019) is radiation perturbations, and as discussed in section 3d, Liu et al. (2018) found that perturbing the radiative fluxes at the top of the atmosphere resulted in $F_{O}$ and $F_{A}$ perturbations of the same sign, which was not the case for other perturbations. Taken together these findings give some support for considering perturbations to the radiative fluxes at the top of the tropical atmosphere a key driver of the first mode.

The SST composites for the second overturning mode shown in Fig. 8d are broadly consistent with ENSO variability, just like the spatial correlation map in Fig. 8d. Moreover, comparing the composites for the first and second mode shows that the SST perturbation of the second mode is about twice as strong as that to the first. This ties back to an earlier discussion we had about the strength of these two modes and how it depends on the metric. The second mode is clearly dominant when looking at SST or $\mathrm{SSH}$, while the first dominates the variability in the MOC and the cross-equatorial energy transports.

An interesting remaining question is why no similar mode is found in the Atlantic Ocean. In fact, there are some indications that a similar although much weaker mode may exist in the Atlantic. Calculating $P_{\text {cent }}$ using values just over the Atlantic sector gives an index that has a correlation coefficient of $r=-0.45$ with $F_{O}^{\text {Atl }}$. That is, the Atlantic Ocean's energy transport is also anticorrelated with $P_{\text {cent }}$ when evaluated only over the Atlantic. However, the Atlantic's $P_{\text {cent }}$ is uncorrelated with the global one, so the interannual ITCZ migrations over the Atlantic Ocean are largely independent from the global ones at zero lag.

\section{Conclusions}

Our analysis suggests that the interannual variability in the atmospheric and Indo-Pacific overturning circulation is dominated by two coupled modes. The first one is related to meridional motion of the ITCZ and the second one to ENSO. The two modes are uncorrelated at zero lag but are significantly correlated with a 1-yr lag. We speculate that asymmetric hemispheric heating during the ENSO cycle might be a way to trigger the first mode. However, the connection between these two modes is still quite obscure, and further research is needed to see if and how they might relate to each other. The structure of both these modes agrees well with earlier inferences about the overturning variability from observations and models (Oort and Yienger 1996; Nguyen et al. 2013; Donohoe et al. 2014; Green and Marshall 2017).

The same variability as in the overturning is also seen in the cross-equatorial energy transports both in the Indo-Pacific and the atmosphere, as well as in the sea level in the tropical Indo-Pacific Ocean. Furthermore, we find the cross-equatorial energy transport in the Indo-Pacific owing to the first mode to be considerably larger than that in the atmosphere and the Atlantic Ocean. This large Indo-Pacific energy transport goes from the hemisphere with low oceanic heat content to that with high oceanic heat content, and we find the transport to be wind-driven in accordance with Green and Marshall (2017).

The scope of this article relates strongly to the quickly expanding literature on the response of the ITCZ position to various different perturbations (see, e.g., Hawcroft et al. 2018; Xiang et al. 2018; Liu et al. 2018; Yu and Pritchard 2019; Green et al. 2019). However, our focus on interannual variability and observations is different from that in those works where the semiequilibrated response of climate models is investigated. A primary finding in these works is that high-latitude radiation perturbations tend to give more ocean-centric responses than low-latitude perturbations, and there is also a tendency for the Atlantic Ocean to respond stronger to high-latitude perturbations. We find, somewhat at odds with these results, that most evidence, such as for example our streamfunction anomalies, which are mostly confined to the tropics, and the absence of an Atlantic response, is incompatible with a high-latitude perturbation. However, the much larger ocean than atmosphere energy fluxes are typical of highlatitude perturbations in these studies. Moreover, we find striking similarities between our SST patterns and those of low-latitude perturbations in Xiang et al. (2018); Yu and Pritchard (2019). It thus appears that although the crossequatorial oscillation has many similarities to these steadystate responses, it is also distinct in some aspects, and a full understanding of the phenomenon is still wanting.

Our results are consistent with earlier estimates showing that the ocean energy transport imposes a considerable damping on meridional ITCZ migrations (Green and Marshall 2017; Schneider 2017). Somewhat different damping coefficients can be arrived at depending on what assumptions one makes and what time scales one considers. For longer time scales, we find a damping coefficient around 3, in excellent agreement with Schneider (2017). On interannual time scales we find that ocean energy storage gives rise to a slightly weaker damping coefficient closer to 2 . 

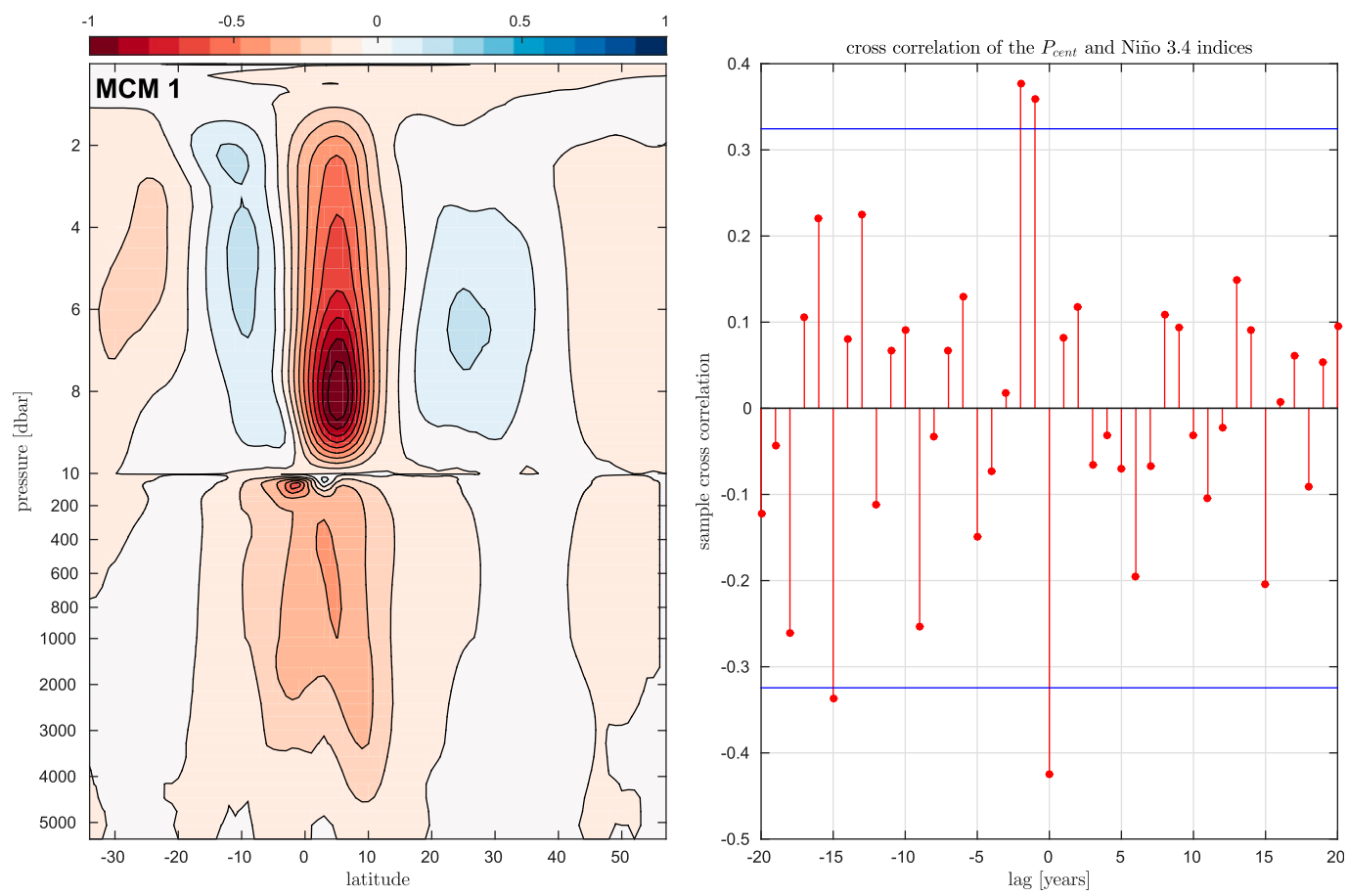

FIG. A1. (left) As in Fig. 2, and (right) as in Fig. 4, but here the years are defined as starting in July and ending in June.

The view that Indo-Pacific ocean energy transport plays a key role for tropical precipitation is corroborated by an examination of the first MC mode of precipitation and the map of correlations between $P_{\text {cent }}$ and the yearly averaged precipitation (see Fig. 7), which both show patterns that are much stronger over the Indo-Pacific Ocean than elsewhere. However, the effects of the atmosphere and the Indo-Pacific Ocean on these patterns are not truly separable in our reanalysis data, since both the atmospheric and the oceanic reanalyses are driven by observations from both the atmosphere and the ocean and are thus neither truly coupled nor truly independent. More work, both observational and with coupled models as well as a more accurate planetary energy budget, is thus needed in order to gain a more mature understanding of this coupled phenomenon.

In conclusion, we find it quite remarkable that such large-scale coupled modes of overturning variability have gotten so little attention, especially in the oceanographic literature. We believe a key reason for this is the comparably small interest in the Indo-Pacific overturning as compared to the Atlantic. This has left the Indo-Pacific overturning as a somewhat overlooked phenomena with a potentially large impact on climate. However, the predominant role of the tropical Pacific for heat export is also highlighted in a recent article by Forget and Ferriera (2019), where a Helmholtz decomposition is used to single out the divergent part of the ocean heat transport, so perhaps the time of the Indo-Pacific is at hand.

Acknowledgments. We thank Michael Mayer for useful hints on how to best compute the cross-equatorial MSE transport. The ERA-Interim data are available at http:// apps.ecmwf.int/datasets/data/interim-full-daily/levtype $=\mathrm{pl} /$, the ORAS4 data at ftp://ftp-icdc.cen.uni-hamburg.de/ EASYInit/ORA-S4/, the ECCO-V4r3 data at https:// ecco.jpl.nasa.gov/products/all/, and the SSALTO/Duacs "all-sat-merged" data are distributed by CMEMS and found at http://marine.copernicus.eu.

\section{APPENDIX A}

\section{A Different Kind of Year}

Figure A1 (left) shows the first MC mode of the overturning circulation in the atmosphere and the IndoPacific Ocean constructed from yearly averaged streamfunction anomalies, like in Fig. 2, but for a year starting in July and ending in June. The first mode accounts for $87 \%$ of the explained squared covariance. The structure of the first atmospheric mode here is very similar to that in Fig. 2, while our first oceanic mode here appears to be a mixture of the first and second mode in 


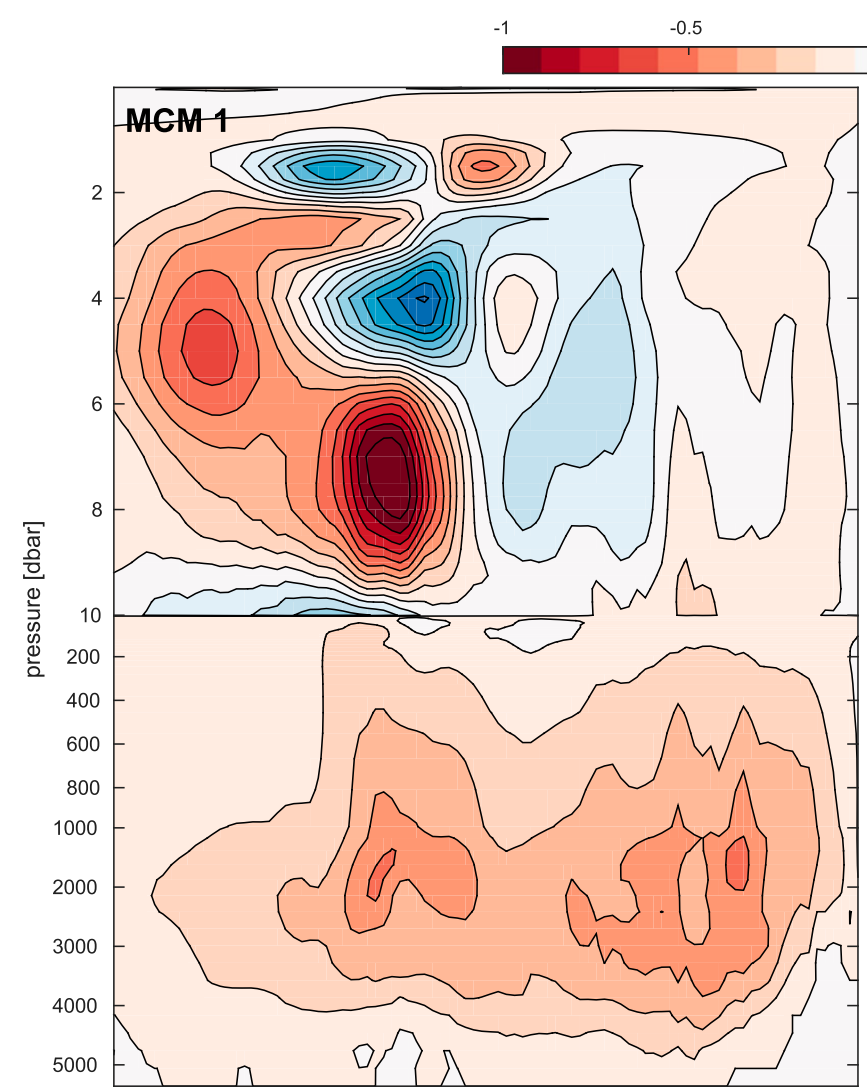

0.5
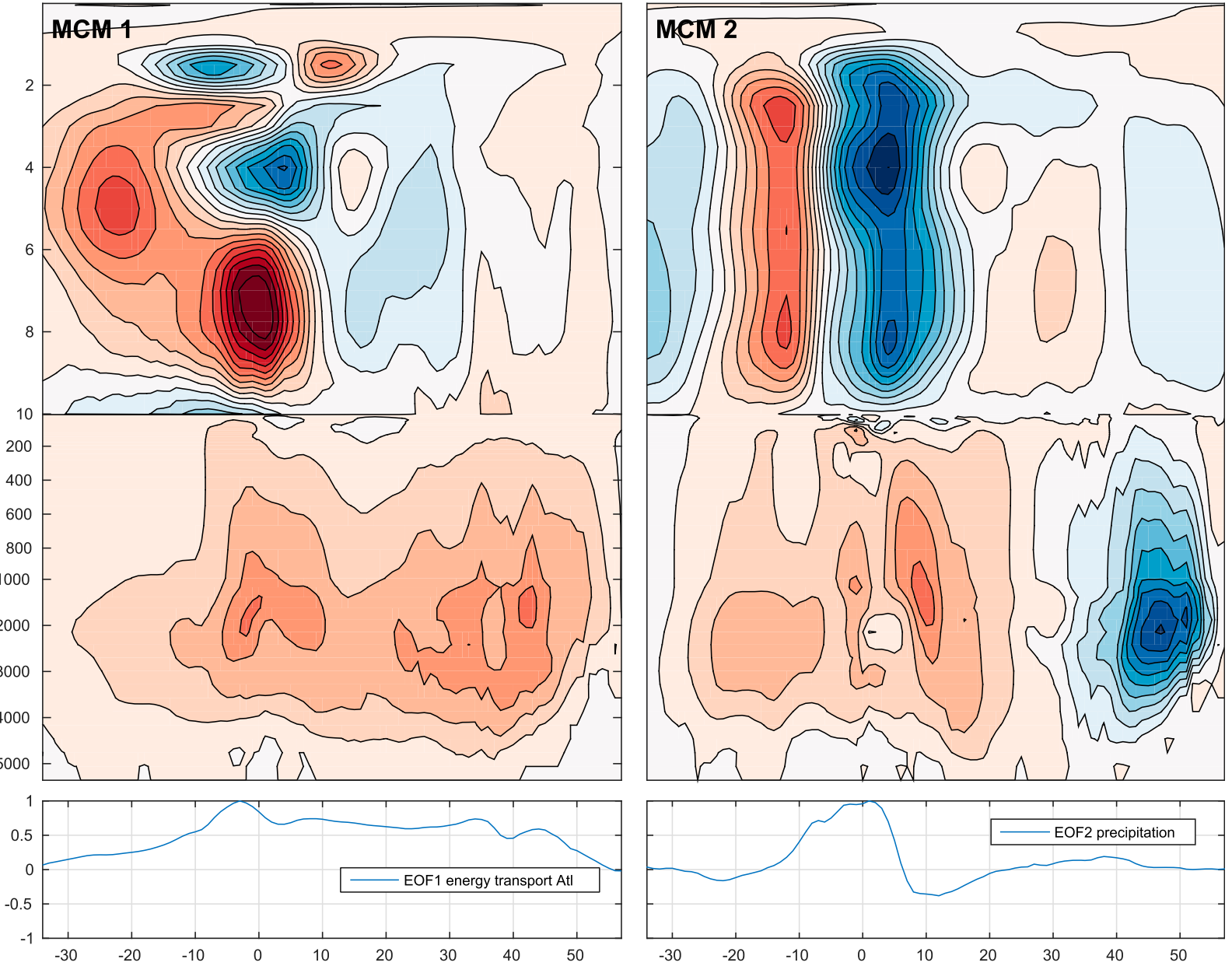

FIG. B1. As in Fig. 2, but for the Atlantic Ocean and the atmosphere. Here there is no energy transport EOF in the left panel and no precipitation EOF in the right one, since neither of the principal components of those EOFs were significantly correlated with those of the MC modes.

Fig. 2. The right panel shows the cross correlation between the Niño-3.4 and the $P_{\text {cent }}$ index for a year starting in July and ending in June. Here we find a moderate anticorrelation at zero lag, which likely explains the mixture of the modes. The first atmospheric mode is strongly anticorrelated to $P_{\text {cent }}(r=-0.81)$ and strongly correlated to the Niño-3.4 index, having $r=-0.78$. The first oceanic similarly has $r=-0.63$ with $P_{\text {cent }}$ and $r=$ 0.86 with the Niño-3.4 index.

\section{APPENDIX B}

\section{Overturning Variability in the Atlantic Ocean}

Figure B1 shows the first two MC modes of the overturning circulation in the atmosphere and Atlantic Ocean constructed from yearly averaged streamfunction anomalies, like in Fig. 2 for the Indo-Pacific Ocean. The first mode accounts for $83 \%$ of the explained squared covariance and the second mode for another $8 \%$. The first atmospheric mode is significantly correlated with $P_{\text {cent }}(r=$ $0.53)$, while the first oceanic mode is not $(r=0.07)$. Neither of these modes are significantly correlated with the Niño3.4 index. However, both the first modes are strongly correlated to an index made up of the numbers $[1,2,3, \ldots, 39]$, having $r=0.64$ for the atmosphere and $r=0.79$ for the ocean. The first MC modes thus seem to describe either a long-term trend or an oscillation with a period that is much longer than our dataset. Either way the first modes seem to have little relevance for our current focus on coupled atmosphere-ocean interannual variability. We have also done this analysis on detrended MOC fields (not shown). This gives a similar picture where the first atmospheric mode is significantly correlated with $P_{\text {cent }}$, while the first 
oceanic mode is not. Moreover, the mode structure from this detrended analysis is similar to that shown in Fig. B1.

The second atmospheric mode is significantly correlated with $P_{\text {cent }}(r=0.77)$, while the second oceanic mode is not $(r=0.2)$. Neither of the second modes is strongly correlated with the Niño-3.4 index. Much like the first set of modes for atmosphere-Atlantic Ocean overturning they seem to be of little relevance for our current focus on coupled atmosphere-ocean interannual variability. This does not mean, however, that the Atlantic Ocean overturning is insensitive to changes in the atmospheric circulation. In fact, it is well known to respond to, for example, changes in the Southern Ocean wind stress (Toggweiler and Samuels 1998; Jochum and Eden 2015). Moreover, the correlation between $P_{\text {cent }}$ calculated just over the Atlantic Ocean and the Atlantic heat transport discussed in section 3e suggests that the interannual variability in the Atlantic Ocean could have similarities to that in the Indo-Pacific. However, to see if those similarities exist one would have to use some other diagnostic than an MCA of the MOC, since the interannual variability in the atmospheric MOC streamfunction is not strongly affected by variations in the Atlantic Ocean.

\section{REFERENCES}

Adam, O., T. Bischoff, and T. Schneider, 2016: Seasonal and interannual variations of the energy flux equator and ITCZ. Part I: Zonally averaged ITCZ position. J. Climate, 29, 3219-3230, https://doi.org/10.1175/JCLI-D-15-0512.1.

Balmaseda, M. A., K. Mogensen, and A. T. Weaver, 2013: Evaluation of the ECMWF ocean reanalysis system ORAS4. Quart. J. Roy. Meteor. Soc., 674, 1132-1161, https://doi.org/10.1002/QJ.2063.

Bender, F. A.-M., A. Engström, R. Wood, and R. J. Charlson, 2017: Evaluation of hemispheric asymmetries in marine could radiative properties. J. Climate, 30, 4131-4147, https://doi.org/ 10.1175/JCLI-D-16-0263.1.

Bischoff, T., and T. Schneider, 2014: Energetic constraints on the position of the intertropical convergence zone. J. Climate, 27, 4937-4951, https://doi.org/10.1175/JCLI-D-13-00650.1.

- , and - 2016: The equatorial energy balance, ITCZ position, and double-ITCZ bifurcations. J. Climate, 29, 2997-3012, https://doi.org/10.1175/JCLI-D-15-0328.1.

Bretherton, C. S., C. Smith, and J. M. Wallace, 1992: An intercomparison of methods for finding coupled patterns in climate data. J. Climate, 5, 541-560, https://doi.org/10.1175/ 1520-0442(1992)005<0541:AIOMFF>2.0.CO;2.

Czaja, A., and C. Frankignoul, 2002: Observed impact of Atlantic SST anomalies on the North Atlantic Oscillation. $J$. Climate, 15, 606-623, https://doi.org/10.1175/1520-0442(2002)015< 0606:OIOASA $>2.0 . \mathrm{CO} ; 2$

_ and J. Marshall, 2006: The partitioning of the poleward heat transport between the atmosphere and ocean. J. Atmos. Sci., 63, 1498-1511, https://doi.org/10.1175/JAS3695.1.

Dai, A., and T. M. L. Wigley, 2000: Global patterns of ENSOinduced precipitation. Geophys. Res. Lett., 27, 1283-1286, https://doi.org/10.1029/1999GL011140.
Dee, D. P., and Coauthors, 2011: The ERA-Interim reanalysis: Configuration and performance of the data assimilation system. Quart. J. Roy. Meteor. Soc., 137, 553-597, https://doi.org/10.1002/QJ.828.

de Lavergne, C., G. Madec, F. Roquet, R. M. Holmes, and T. J. McDougall, 2017: Abyssal ocean overturning shaped by seafloor distribution. Nature, 551, 181-186, https://doi.org/10. 1038/NATURE24472.

Donohoe, A., J. Marshall, D. Ferreira, and D. McGee, 2013: The relationship between ITCZ location and cross-equatorial atmospheric heat transport: From the seasonal cycle to the last glacial maximum. J. Climate, 26, 3597-3618, https://doi.org/ 10.1175/JCLI-D-12-00467.1.

,,,--- K. Armour, and D. McGee, 2014: The interannual variability of tropical precipitation and interhemispheric energy transport. J. Climate, 27, 3377-3392, https://doi.org/ 10.1175/JCLI-D-13-00499.1.

Fasullo, J. T., and K. E. Trenberth, 2008: The annual cycle of the energy budget. Part I: Global mean and land-ocean exchanges. J. Climate, 21, 2297-2312, https://doi.org/10.1175/2007JCLI1935.1.

Ferrari, R., M. F. Jansen, J. F. Adkins, A. Burke, A. L. Stewart, and A. F. Thompson, 2014: Antarctic sea ice control on the ocean circulation in present and glacial climates. Proc. Natl. Acad. Sci. USA, 24, 8753-8758, https://doi.org/10.1073/PNAS.1323922111.

Forget, G., and D. Ferriera, 2019: Global ocean heat transport dominated by heat export from the tropical Pacific. Nat. Geosci., 12, 351-354, https://doi.org/10.1038/s41561-019-0333-7.

_ J.-M. Campin, P. Heimbach, C. N. Hill, R. M. Ponte, and C. Wunch, 2015: ECCO version 4: An integrated framework for non-linear inverse modeling and global ocean state estimation. Geosci. Model Dev., 8, 3071-3104, https://doi.org/ 10.5194/gmd-8-3071-2015.

Frierson, D. M. W., and Coauthors, 2013: Contribution of ocean overturning circulation to tropical rainfall peak in the Northern Hemisphere. Nat. Geosci., 1, 940-944, https://doi.org/ 10.1038/NGEO1987.

Fukumori, I., O. Wang, I. Fenty, G. Forget, P. Heimbach, and R. M. Ponte, 2017: ECCO version 4 release 3. NASA JPL Tech. Rep., https://doi.org/1721.1/110380.

Gent, P. R., and J. C. McWilliams, 1990: Isopycnal mixing in ocean circulation models. J. Phys. Oceanogr., 20, 150-155, https:// doi.org/10.1175/1520-0485(1990)020<0150:IMIOCM > 2.0.CO;2.

Green, B., and J. Marshall, 2017: Coupling of trade winds with ocean circulation damps ITCZ shifts. J. Climate, 30, 43954411, https://doi.org/10.1175/JCLI-D-16-0818.1.

—, _ and J.-M. Campin, 2019: The 'sticky' ITCZ: Ocean moderated ITCZ shifts. Climate Dyn., 53,1-19, https://doi.org/ 10.1007/S00382-019-04623-5.

Griffies, S. M., and R. J. Greatbatch, 2012: Physical processes that impact the evolution of global mean sea level in ocean climate models. Ocean Modell., 51, 37-72, https://doi.org/10.1016/ j.ocemod.2012.04.003.

Hannachi, A., I. T. Jolliffe, and D. B. Stephenson, 2007: Empirical orthogonal functions and related techniques in atmospheric science: A review. Int. J. Climatol., 27, 1119-1152, https:// doi.org/10.1002/JOC.1499.

Hawcroft, M., J. M. Haywood, M. Collins, A. Jones, A. C. Jones, and G. Stephens, 2017: Southern Ocean albedo, interhemispheric energy transports and the double ITCZ: Global impacts of biases in a coupled model. Climate Dyn., 48, 22792295, https://doi.org/10.1007/S00382-016-3205-5.

,,,--- and,- 2018 : The contrasting response to tropical and extratropical energy perturbations. Climate Dyn., 51, 3231-3249, https://doi.org/10.1007/s00382-018-4076-8. 
Held, I. M., 2001: The partitioning of the poleward energy transport between the tropical ocean and atmosphere. J. Atmos. Sci., 58, 943-948, https://doi.org/10.1175/1520-0469(2001) 058<0943:TPOTPE $>2.0 . \mathrm{CO} ; 2$.

Hieronymus, M., and J. Nycander, 2013: The budgets of heat and salinity in NEMO. Ocean Modell., 67, 28-38, https://doi.org/ 10.1016/J.OCEMOD.2013.03.006.

—, _ J. Nilsson, K. Döös, and R. Hallberg, 2019: Oceanic overturning and heat transport: The role of background diffusivity. J. Climate, 32, 701-716, https://doi.org/10.1175/JCLI-D-18-0438.1.

Jin, F.-F., 1997: An equatorial ocean recharge paradigm for ENSO. Part I: Conceptual model. J. Atmos. Sci., 54, 811-829, https:/ doi.org/10.1175/1520-0469(1997)054<0811:AEORPF>2.0.CO;2.

Jochum, M., and C. Eden, 2015: The connection between Southern Ocean winds, the Atlantic meridional overturning circulation and Indo-Pacific upwelling. J. Climate, 28, 9250-9257, https:// doi.org/10.1175/JCLI-D-15-0263.1.

Kang, S. M., I. M. Held, D. M. W. Frierson, and M. Zhao, 2008: The response of the ITCZ to extratropical thermal forcing: Idealized slab-ocean experiment with a GCM. J. Climate, 21, 35213532, https://doi.org/10.1175/2007JCLI2146.1.

_ - Y. Shin, and S.-P. Xie, 2018: Extratropical forcing and tropical rainfall distribution: Energetics framework and ocean Ekman advection. npj Climate Atmos. Sci., 1, 20172, https:// doi.org/10.1038/S41612-017-0004-6.

Kay, J. E., C. Wall, V. Yettella, B. Medeiros, C. Hannay, P. Caldwell, and C. Bitz, 2016: Global climate impacts of fixing the Southern Ocean shortwave radiation bias in the Community Earth System Model (CESM). J. Climate, 29, 4617-4636, https://doi.org/10.1175/JCLI-D-15-0358.1.

Klein, S. A., and D. L. Hartmann, 1993: The seasonal cycle of low stratiform clouds. J. Climate, 6, 1587-1606, https://doi.org/ 10.1175/1520-0442(1993)006<1587:TSCOLS $>2.0$.CO;2.

Köhl, A., 2014: Detecting processes contributing to interannual halosteric and thermosteric sea level variability. J. Climate, 27, 2417-2426, https://doi.org/10.1175/JCLI-D-13-00412.1.

Liu, X., D. S. Battisti, and A. Donohoe, 2017: Tropical precipitation and cross-equatorial ocean heat transport during the mid-Holocene. J. Climate, 30, 3529-3547, https://doi.org/ 10.1175/JCLI-D-16-0502.1.

Liu, Z., C. He, and F. Lu, 2018: Local and remote responses of atmospheric and oceanic heat transports to climate forcing: Compensation versus collaboration. J. Climate, 31, 6445-6460, https://doi.org/10.1175/JCLI-D-17-0675.1.

Loeb, N. G., D. A. Rutan, S. Kato, and W. Wang, 2014: Observing interannual variations in Hadley circulation atmospheric diabatic heating and circulation strength. J. Climate, 27, 41394158, https://doi.org/10.1175/JCLI-D-13-00656.1.

Marshall, J., and K. Speer, 2012: Closure of the meridional overturning circulation through Southern Ocean upwelling. Nat. Geosci., 5, 171-180, https://doi.org/10.1038/NGEO1391.

— A. Donohoe, D. Ferreira, and D. McGee, 2014: The ocean's role in setting the mean position of the inter-tropical convergence zone. Climate Dyn., 42, 1967-1979, https://doi.org/ 10.1007/s00382-013-1767-z.

Mayer, M., and L. Haimberger, 2012: Poleward atmospheric energy transports and their variability as evaluated from ECMWF reanalysis data. J. Climate, 25, 734-752, https:// doi.org/10.1175/JCLI-D-11-00202.1.

, — - J. M. Edwards, and P. Hyder, 2017: Toward consistent diagnostics of the coupled atmosphere and ocean energy budgets. J. Climate, 30, 9225-9246, https://doi.org/10.1175/ JCLI-D-17-0137.1.
Meinen, C. S., and M. J. McPhaden, 2000: Observations of warm water volume changes in the equatorial Pacific and their relationship to El Niño and La Niña. J. Climate, 13, 3551-3559, https://doi.org/ 10.1175/1520-0442(2000)013<3551:OOWWVC > 2.0.CO;2.

Merryfield, W. J., and G. J. Boer, 2004: Variability of upper Pacific Ocean overturning in a coupled climate model. J. Climate, 14, 666-683, https://doi.org/10.1175/JCLI-3282.1.

Miyama, T., J. P. McCready, T. G. Jensen, J. Loschnigg, S. Godfrey, and A. Ishida, 2003: Structure and dynamics of the Indian-Ocean cross equatorial cell. Deep-Sea Res., 50, 20232047, https://doi.org/10.1016/S0967-0645(03)00044-4.

Monahan, A. H., J. C. Fyfe, M. H. P. Ambaum, D. B. Stephenson, and G. R. North, 2009: Empirical orthogonal functions: The medium is the message. J. Climate, 22, 6501-6514, https:// doi.org/10.1175/2009JCLI3062.1.

Nerem, R. S., D. P. Chambers, E. W. Leuliette, G. T. Mitchum, and B. S. Giese, 1999: Variations in global mean sea level associated with the 1997-1998 ENSO event: Implications for measuring long term sea level change. Geophys. Res. Lett., 26, 3005-3008, https://doi.org/10.1029/1999GL002311.

Nguyen, H., A. Evans, C. Lucas, I. Smith, and B. Timbal, 2013: The Hadley circulation in reanalyses: Climatology, variability and change. J. Climate, 26, 3357-3376, https://doi.org/10.1175/ JCLI-D-12-00224.1.

Nilsson, J., and H. Körnich, 2008: A conceptual model of the surface salinity distribution in the oceanic Hadley cell. J. Climate, 21, 6586-6598, https://doi.org/10.1175/2008JCLI2284.1.

Oort, A. H., and J. J. Yienger, 1996: Observed interannual variability in the Hadley circulation and its connection to ENSO. $J$. Climate, 9, 2751-2767, https://doi.org/10.1175/1520-0442(1996)009< 2751:OIVITH $>2.0 . \mathrm{CO} ; 2$.

Schneider, T., 2017: Feedback of atmosphere-ocean coupling on shifts on the intertropical convergence zone. Geophys. Res. Lett., 44, 11 644-11 653, https://doi.org/10.1002/2017GL075817.

, T. Bischoff, and G. H. Haug, 2014: Migrations and dynamics of the intertropical convergence zone. Nature, 513, 45-53, https://doi.org/10.1038/NATURE13636.

Schott, F. A., M. Dengler, and R. Schoenefeldt, 2002: The shallow overturning circulation of the Indian Ocean. Prog. Oceanogr., 53, 57-103, https://doi.org/10.1016/S0079-6611(02)00039-3.

_ S.-P. Xie, and J. P. McCreary Jr., 2009: Indian Ocean circulation and climate variability. Rev. Geophys., 47, RG1002, https://doi.org/10.1029/2007RG000245.

Sullivan, A., J.-J. Luo, A. C. Hirst, D. Bi, W. Cai, and J. He, 2016: Robust contribution of decadal anomalies to the frequency of central-Pacific El Niño. Sci. Rep., 6, 38540, https://doi.org/ 10.1038/srep38540.

Talley, L. D., 2013: Closure of the global overturning circulation through the Indian, Pacific and Southern Oceans: Schematics and transports. Oceanography, 26, 80-97, https://doi.org/ 10.5670/OCEANOG.2013.07.

Toggweiler, J. R., and B. Samuels, 1998: On the ocean's large-scale circulation in the limit off no vertical mixing. J. Phys. Oceanogr., 28, 1832-1852, https://doi.org/10.1175/1520-0485(1998) $028<1832$ :OTOSLS $>2.0$.CO;2.

Tomas, R. A., C. Deser, and S. Lantao, 2016: The role of ocean heat transport in the global climate response to projected Arctic sea ice loss. J. Climate, 29, 6841-6859, https://doi.org/10.1175/ JCLI-D-15-0651.1.

Trenberth, K. E., 1991: Climate diagnostics from global analyses: Conservation of mass in ECMWF analyses. J. Climate, 4, 707-722, https://doi.org/10.1175/1520-0442(1991)004<0707: CDFGAC $>2.0 . \mathrm{CO} ; 2$ 
Vallis, G. K., and R. Farneti, 2009: Meridional energy transport in a coupled atmosphere-ocean system: Scaling and numerical experiments. Quart. J. Roy. Meteor. Soc., 135, 1643-1660, https://doi.org/10.1002/qj.498.

Vinogradova, N. T., R. M. Ponte, and D. Stammer, 2007: Relation between sea level and bottom pressure and the vertical dependence of oceanic variability. Geophys. Res. Lett., 34, L03608, https://doi.org/10.1029/2006GL028588.

Williams, R. G., V. Roussenov, D. Smith, and M. S. Lozier, 2014: Decadal evolution of ocean thermal anomalies in the North Atlantic: The effects of Ekman, overturning and horizontal transport. J. Climate, 27, 698-719, https://doi.org/10.1175/ JCLI-D-12-00234.1.
Wyrtki, K., 1985: Water displacement in the Pacific and the genesis of El Niño. J. Geophys. Res., 90, 7129-7132, https://doi.org/ 10.1029/JC090iC04p07129.

Xiang, B., M. Zhao, Y. Ming, W. Yu, and S. M. Kang, 2018: Contrasting impacts of radiative forcing in the Southern Ocean versus southern tropics on ITCZ position and energy transport in one GFDL climate model. J. Climate, 31, 5609-5628, https:// doi.org/10.1175/JCLI-D-17-0566.1.

Yu, S., and M. S. Pritchard, 2019: A strong role for the AMOC in partitioning global energy transport and shifting ITCZ position in response to latitudinally discrete solar forcing in CESM1.2. J. Climate, 32, 2207-2226, https://doi.org/10.1175/ JCLI-D-18-0360.1. 